Portland State University

PDXScholar

$12-2-1992$

\title{
Speaker Preferences of Listening Behaviors that Lead to Perceived Listening : A Pre-condition of Perceived Understanding
}

Christine M. Carpenter

Portland State University

Follow this and additional works at: https://pdxscholar.library.pdx.edu/open_access_etds

Part of the Other Communication Commons, and the Speech and Rhetorical Studies Commons Let us know how access to this document benefits you.

Recommended Citation

Carpenter, Christine M., "Speaker Preferences of Listening Behaviors that Lead to Perceived Listening : A Pre-condition of Perceived Understanding" (1992). Dissertations and Theses. Paper 4522.

https://doi.org/10.15760/etd.6406

This Thesis is brought to you for free and open access. It has been accepted for inclusion in Dissertations and Theses by an authorized administrator of PDXScholar. Please contact us if we can make this document more accessible: pdxscholar@pdx.edu. 
AN ABSTRACT OF THE THESIS OF Christine M. Carpenter for the Master of Science in Speech Communication presented December 2, 1992.

Title: Speaker Preferences of Listening Behaviors That Lead to Perceived Listening: A Pre-condition of Perceived Understanding.

\section{APPROVED BY THE MEMBERS OF THE THESIS COMMITTEE:}

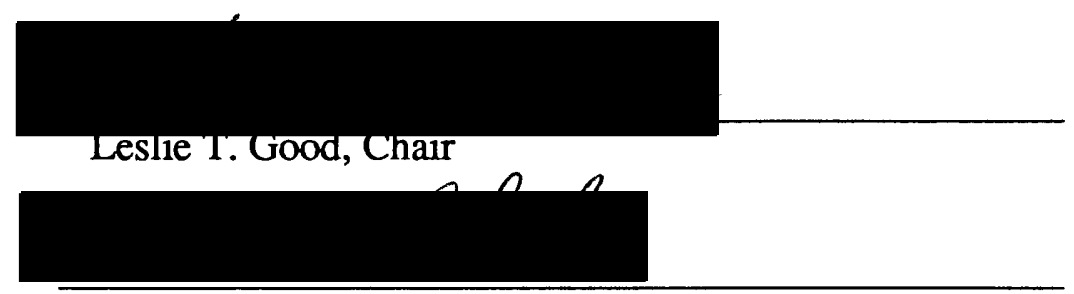

L. David Ritchie

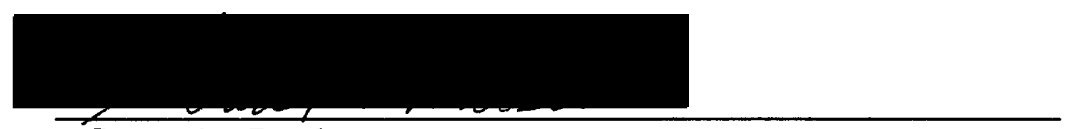

Susan B. Poulsen

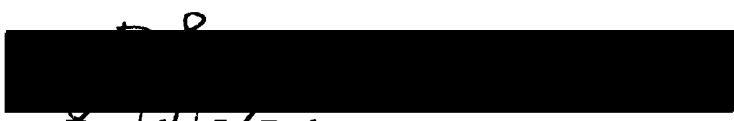

Douglas $Z$. Robertson

When attempting to communicate with another person, the success or failure that a communicator perceives, he or she interprets as understanding or misunderstanding. Research has shown that "perceived understanding" or the "feeling of being understood" is important in self-concept development. However, for some time researchers have focused on the listener's needs and the speaker's needs have been given less attention. Yet, the listener's role in meeting the speaker's needs, particularly in providing feedback to the speaker, is of utmost importance if the speaker is to have the "feeling of being understood." This research examined the concept of the "feeling of being listened to," as it relates to the "feeling of being understood." Eye contact, vocalics, and head nods were examined as 
listener behaviors that affect "perceived listening." Alone, in a private room, each subject viewed a randomly-assigned videotape, imagining him- or herself as the speaker, thus, taking the speaker's perspective. The videotape showed the listener, who responded to the speaker with none, one, or all three nonverbal behaviors being tested. Immediately after viewing the videotape, subjects completed two instruments that identified the probability of eye contact, vocalics, and head nods, as pre-conditions of "perceived listening" and "perceived listening" as a pre-condition of "perceived understanding." Tests of the first four hypotheses about the relationship between nonverbal behaviors and perceived listening were non-significant. The test of the fifth hypothesis about the correlation between perceived listening and perceived understanding was significant, but there was some indication that these two concepts may be redundant. A post-hoc analysis of the relationship between nonverbal behaviors and perceived understanding yielded nonsignificant results, supporting the concern that perceived listening and perceived understanding may be redundant concepts. 
SPEAKER PREFERENCES OF LISTENING BEHAVIORS THAT LEAD

TO PERCEIVED LISTENING: A PRE-CONDITION OF

PERCEIVED UNDERSTANDING

by

CHRISTINE M. CARPENTER

A thesis submitted in partial fulfillment of the requirements for the degree of

\author{
MASTER OF SCIENCE \\ in \\ SPEECH COMMUNICATION
}

Portland State University

1993 


\section{TO THE OFFICE OF GRADUATE STUDIES:}

The members of the Committee approve the thesis of Christine M. Carpenter presented December 2, 1992.
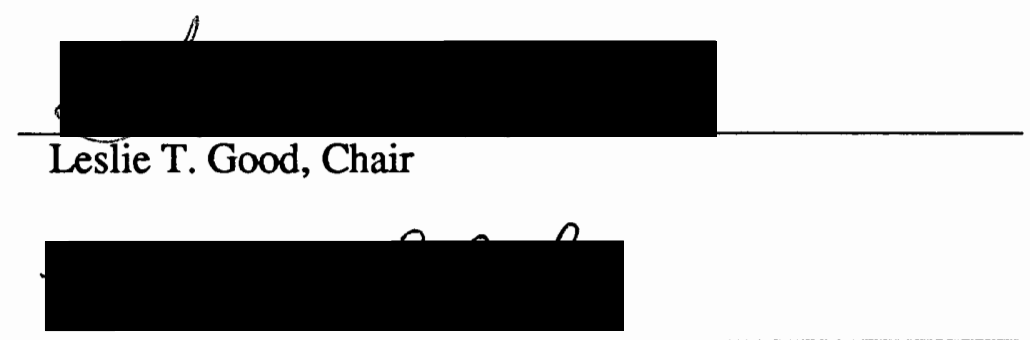

L. David Ritchie

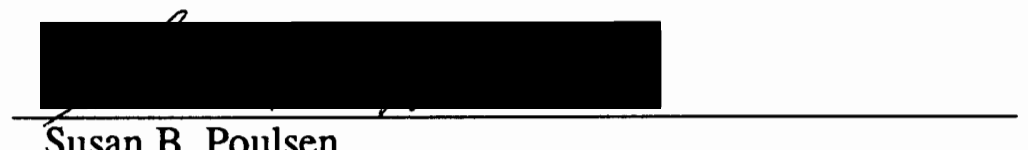

Susan B. Poulsen

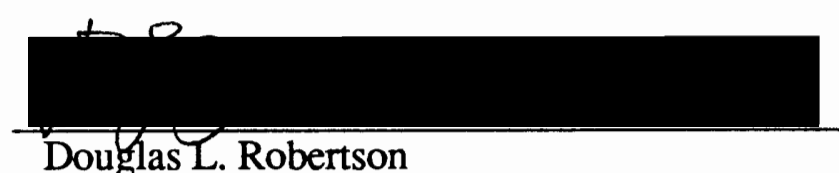

APPROVED:

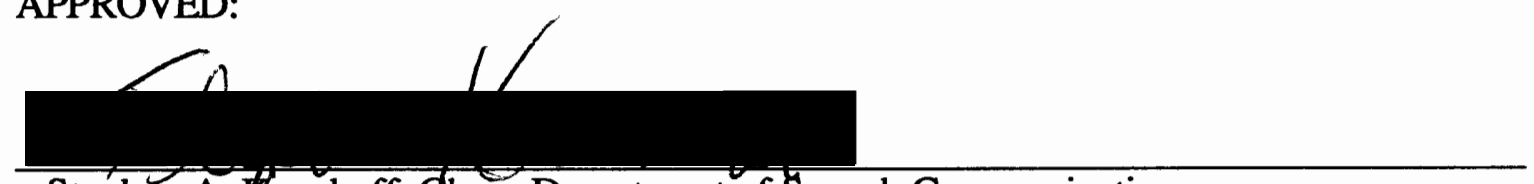

Stephen A. Kosokoff, Qhair, Department of Speech Communication

Roy W. Koch, Vice Provost for Graduate Studies and Research 
TABLE OF CONTENTS

PAGE

LIST OF TABLES ............................................................... vi

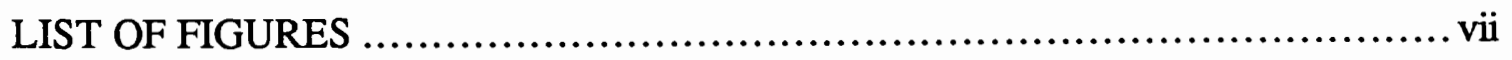

\section{CHAPTER}

I INTRODUCTION .............................................. 1

II REVIEW OF LITERATURE ...................................5

Introduction ............................................. 5

Self-Concept .............................................5

Being Perceived ............................................ 7

Perceived Understanding .................................... 8

Understanding

Being Understood

The Feeling of Being Understood

Perceived Listening ....................................... 16

The Listener

Listener's Nonverbal Feedback Behaviors.................... 18

Eye Contact

Vocalics

Head Nods

III METHOD AND PROCEDURE .................................25

Introduction .................................................. 25

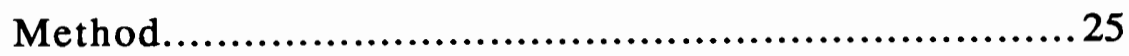

Design

Participants

Measurement Instruments 
Procedure...................................................... 34

Recruitment

Process

IV $\quad$ RESULTS......................................................... 36

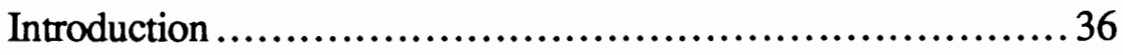

Manipulation Check...................................... 36

Scales..................................................... 37

Research Hypotheses Tests .................................. 37

Post Hoc Analysis................................................. 41

$\mathrm{V}$ DISCUSSION AND CONCLUSIONS ............................4 44

Introduction ............................................ 44

Discussion.................................................... 44

Implications of the Findings

Study Limitations................................................ 46

Threats to Internal Validity

Threats to External Validity

Suggestions for Future Research

Conclusions and Suggestions......................................... 61

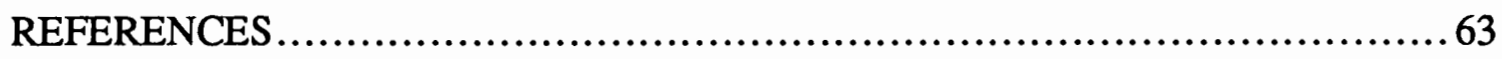

APPENDICES

A PILOT STUDY QUESTIONNAIRE ............................ 71

B PERCEIVED LISTENING INSTRUMENT .........................73

C PERCEIVED UNDERSTANDING INSTRUMENT ..................75

D AUDIO-TAPED INSTRUCTIONS SCRIPT.............................77

E INFORMED CONSENT........................................ 85 
F INFORMATION SHEET ....................................... 87

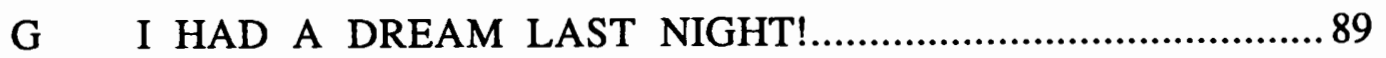

H MANIPULATION CHECK QUESTIONNAIRE.......................... 91 


\section{LIST OF TABLES}

TABLE

PAGE

I Subject Distribution Between Listener's Nonverbal Behaviors............. 26

II Subject Information by Major, Cultural Background,

Age, and Gender ......................................... 28

III Perceived Listening Items ...................................... 30

IV Listening Understanding Items ................................. 31

V Perceived Understanding Instrument Understanding Items............. 32

VI Perceived Understanding Instrument Misunderstanding Items ...........33

VII Manipulation Check Means and Medians for Eye Contact, Vocalics, and Head Nods, by Condition................................ 38

VIII Analysis of Variance: Five Nonverbal Conditions for Perceived

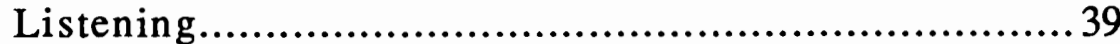

IX Means and Cell Size of Five Nonverbal Conditions for Perceived Listening .................................................. 40

$\mathrm{X}$ Analysis of Variance: Five Nonverbal Conditions for Perceived Understanding ............................................ 42

XI Means and Cell Size of Five Nonverbal Conditions for Perceived Understanding 


\section{LIST OF FIGURES}

FIGURE

PAGE

1. Model of Nonverbal Communication Stages and Influences on

Speaker's Self-Concept............................................6 


\section{CHAPTER I}

\section{INTRODUCTION}

For centuries scholars have been discussing and studying the area of "understanding," but only in the last few decades have various disciplines seriously pursued the concept. However, it is within the last decade that the field of speech communication has begun generating research and literature in the area of understanding.

Initially, understanding was thought to be a form of empathy. However, a convincing argument has been made for the distinction between empathy and understanding (Laing, Phillipson \& Lee, 1966; von Wright, 1971). Therefore, it is from this separative perspective that the scholarly evolution of understanding will be discussed, as it relates to the field of communication. It must also be acknowledged that misunderstanding is the inverse of understanding, and that the concept of misunderstanding is equally important and when it is not mentioned along with understanding it is implied.

The research concept of "feeling understood" was introduced to the field of speech communication by Cahn (1981). His paper called for a shift in research, to examine communicator feelings instead of the research focus of empathy and the focus on feelings of "the other." He defined feeling understood-misunderstood as "the respondent's assessment of his or her own feelings (feeling understood-misunderstood)" (p. 2). His more comprehensive definition is "An inference based on cues, feeling understoodmisunderstood refers to the communicator's assessment of his or her success or failure when attempting to communicate with another person" (p. 1). In addition, he analyzed and evaluated the concept as a viable construct for communication researchers. 
In an oral communication dyad, before the speaker has the "feeling of being understood," the speaker may need to have the "feeling of being listened to." Within communication the process most used is listening (Brown, 1982; Keefe, 1971; Rankin, 1926; Weinrauch \& Swanda, Jr., 1975). While listening definitions abound, a consensus has not emerged on what listening actually is (Witkin, 1990; Rubin \& Roberts, 1987). As a sample, Wolvin and Coakley (1982) listed 16 definitions before they settled on listening being "the process of receiving, attending to, and assigning meaning to an aural stimuli" (p. 52). A more thorough definition came from Barker (1984), in which his listening composite included: hearing, perceiving, attending to, comprehending, remembering, and responding appropriately.

Research in the area of listening is still in the infancy stage (Coakley \& Wolvin, 1990; Rhodes, Watson \& Barker, 1990; Witkin, 1990; Rubin \& Roberts, 1987), and the limited amount of research being done generally focuses on what the listener is getting from the speaker. Most studies using instruments test listening comprehension and critical thinking skills (Brown \& Carlsen, 1955; Watson \& Barker, 1983; Bostrom \& Waldhart, 1980; Rubin, 1982a \& b). Such studies test long-term and short-term memory retention of listeners, but do not address the complexity of the listening interaction between the listener and the speaker.

Watzlawick, Beavin and Jackson (1967) argued that an individual "cannot not communicate." While the speaker is sending the message to the listener, the listener is simultaneously sending a message to the speaker. The listener's silent message to the speaker is vital feedback, even as the speaker speaks. Communication research has not addressed this issue adequately because the communication researcher has focused on the speaker as sender, rather than the listener as sender.

"Perceived listening" focuses on the speaker's "feeling of being listened to," in the same way Cahn's Theory of Perceived Understanding focuses on the speaker's "feeling of 
being understood." The concept of the speaker "feeling understood" may positively correlate with the speaker "feeling of being listened to," and "perceived listening" may precede "perceived understanding." In addition, it is important to identify the specific variables present when an individual has the "feeling of being understood" or the "feeling of being listened to."

While there is a paucity of literature in the area of "perceived understanding," even less attention has been given to "perceived listening." However, a few researchers are beginning to address the subject of listener behavior effects on the speaker. Rubin (1982b) vaguely acknowledged this in her outline referring to the use of appropriate nonverbal signs: "Recognize and/or use appropriate gestures, eye contact, and facial expressions when communicating understanding or lack of understanding in a listening situation" (p. 22).

In addition, Brownell (1990) considered the perceptions that subordinates had of their managers' listening behaviors. She found that women listeners provided stronger nonverbal cues than listening men. Her list included the perception of attentiveness, which the women, especially, demonstrated through responses of eye contact, head nods, and smiling. Similarly, Tannen $(1986,1990)$ argued that women display more overt behaviors associated with listening, such as head nods, "uhuhs," and eye contact.

In short, much research focus on listening has been directed toward the listener's needs to comprehend and retain the speaker's message, and little attention has been given to the speaker's needs. Taking the perspective that listener feedback affects the speaker, perhaps Barker's (1984) definition of listening could be adapted to reflect what the speaker needs from a listener. Where the listener needs to be hearing, the speaker needs to be heard. When the listener needs to be perceiving, the speaker needs to be perceived. While the listener needs to be attending to, the speaker needs to be attended to. As the listener is comprehending, the speaker needs to be comprehended. The listener needs to focus on 
remembering, and the speaker needs to be remembered. Most important to the concept of perceived listening, the listener needs to give attention to responding appropriately, and the speaker needs to be responded to appropriately.

The focus of this research was to explore the significance of eye contact, vocalics, and head nods as listener behaviors that affect the speaker's "feeling of being listened to," and to examine the concept of the "feeling of being listened to," as it relates to the "feeling of being understood." As cited in the literature and reported by respondents of a pilot study for this research, eye contact, vocalics and head nods are the three behaviors most often associated with nonverbal feedback. Earlier research has been limited in its examination of the effects of nonverbal feedback on the speaker's feeling of being listened to. In addition, research in the area of the concept of the speaker's feeling of being listened to as a precondition of the speaker's feeling of being understood has been limited.

The following chapters will include a review of literature, methods, results, and discussion and conclusions. The literature review in Chapter Two develops the rationale for this research and also elaborates on the model being tested. In Chapter Three descriptions are given of the subjects and the procedures used to test the model. The specific findings of the study are reported in Chapter Four. The final chapter discusses the implications of the results, the study limitations, suggestions for future research, and conclusions. 


\section{CHAPTER II}

\section{REVIEW OF LITERATURE}

\section{INTRODUCTION}

After a review of literature and a pilot study, this researcher theorized that eye contact, vocalics, and head nods are both independent and additive in their effects on the speaker's feeling of being listened to, and that the speaker's feeling of being listened to is a pre-condition of the speaker's feeling of being understood. As no previous research had been done comparing the feeling of being listened to with the feeling of being understood, a model was developed (see Figure 1). The model is an integration and theoretical extension of the relevant literature, this researcher's pilot study, and logic. The following is a discussion of the elements of the model.

\section{SELF-CONCEPT}

"The self-concept is a relatively stable set of perceptions individuals hold about themselves" (Adler \& Towne, 1990, p. 71). However, at birth, individuals have no concept of self, nor do they have any self-esteem (Rogers, 1951). As the individual matures, the self-concept and self-esteem is intersubjectively or interactively developed by internalizing the conscious perceptions the individual has about the way others perceive him or her (Mead, 1934). The self-concept continually develops over a person's lifetime (Combs \& Snygg, 1959; Rogers, 1951). An individual's identities and self-evaluations are the core of his or her self-concept. This image of "self" is contained and maintained in the 


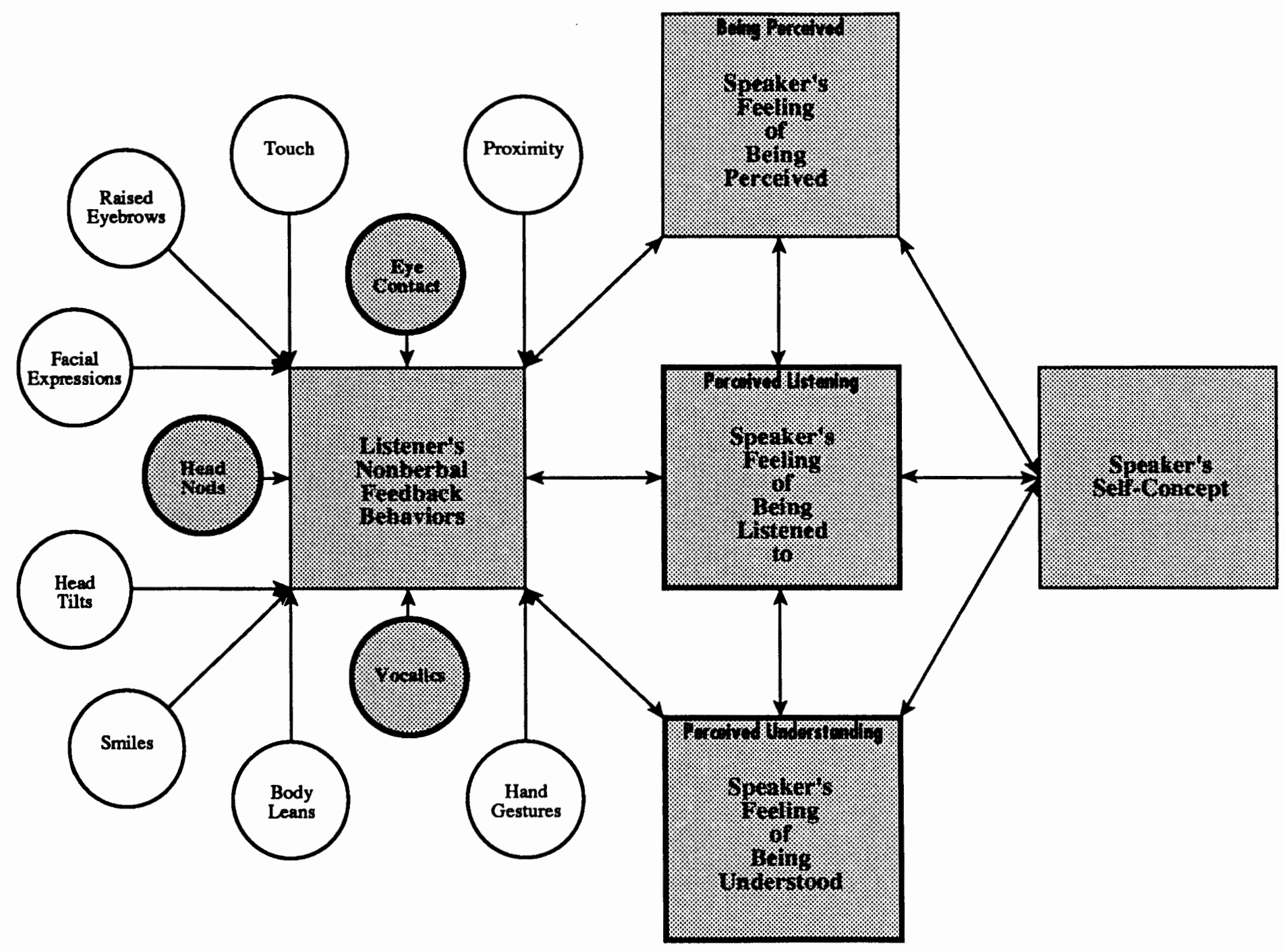

Figure 1. Model of Nonverbal Communication Stages and Influences on Speaker's Self-Concept. 
this level of being perceived, the passerby acknowledges your presence by eye contact, a nod, a smile or a brief vocal greeting.

Having moved from the mental awareness of recognition to the cognitive agreement state of acknowledgment, the "feeling of being perceived" is possible. At this final level an emotional state is experienced internally. A feeling of "endorsement" or self-worth as a person may correspond to the "feeling of being perceived." Again, Cissna and Sieburg's (1986) ideas of self-concept support which include recognition, acknowledgment, and endorsement may relate to the "feeling of being perceived," as shown in Figure 1.

\section{PERCEIVED UNDERSTANDING}

Another important component that influences self-concept is perceived understanding (Cushman \& Cahn, 1985; Cahn, 1987a). Individuals compare their own perspectives to the perspectives of other individuals to assess their own levels of perceived understanding. Three levels of perceived understanding have been identified (Laing, Phillipson \& Lee, 1966). The first level of perceived understanding is attained through the mental state of comprehension, "understanding." The second level of perceived understanding is "being understood," and is attained through cognitive agreement. In the third level of perceived understanding an emotional state is reached, resulting in "the feeling of being understood."

Each of the preceding levels is a precondition for the next level. The ultimate level of perceived understanding is that of "the feeling of being understood." Figure 1 illustrates the role of "the feeling of being understood" as it relates to the speaker's self-concept.

\section{Understanding}

"Understanding" from the perspective of social psychology is defined by Laing, Phillipson and Lee (1966) as "the conjunction between the metaperspective of one person 
mind (Phillips \& Metzgar, 1976). "The mind can be defined as the process of interacting with oneself...'Minding' involves hesitating (postponing overt action) while one consciously assigns meaning to the stimuli" (Littlejohn, 1989, p. 99).

The messages and experiences an individual has with significant others, in particular, are of great influence on self-concept development. Self-concept undergoes continual development and refinement as a result of human interaction. Rogers (1951) argued that an individual evaluates every experience in relation to his or her self-concept. In this way, communication experiences not only affect self-concept, but communication experiences are affected by an individual's self-concept.

Combs and Snygg (1959) argued that the self-concept is "multifaceted." Individuals move in and out of different facets of themselves as the situation changes. They may be honest with their real perceived self, optimistic about their desired self, and careful to gain approval through their presenting self.

According to Phillips \& Metzgar (1976), "the most important goal of an interpersonal rhetoric is enhancement of self-esteem" (p. 133). Both verbal and nonverbal messages shape the self-concept that is almost totally a product of interaction with others. The speaker's self-concept is influenced by a variety of things, but several especially important aspects have been isolated (see Figure 1).

\section{BEING PERCEIVED}

Cissna and Sieburg's (1986) ideas of self-concept support include recognition, acknowledgment, and endorsement. Recognition or a mental awareness of being perceived may precede the "feeling of being perceived." For example, someone passing you on the sidewalk may look at you as a normal process to avoid bumping into another pedestrian.

Beyond the mental awareness or recognition is actual acknowledgment. Progressing toward the "feeling of being perceived," cognitive agreement takes place. At 
and the direct perspective of the other" (p. 29). Simply, if A and B represent individuals, and X any object or concept, direct perspective is A's view of X. Metaperspective is A's view of B's view of $X$. When A's view of B's view of X agrees with B's view of $X$, "understanding" occurs. Being "aware" of the other's point of view equates to this level of "understanding."

Laing, Phillipson and Lee (1966) applied this model of understanding to married couples. The nondisturbed marriages showed the spouses feelings of understanding to be relatively equal. In both disturbed and nondisturbed marriages, couples who disagreed upon specific areas reported more feelings of misunderstanding with their spouses, regarding those particular areas.

Searle (1970), a philosopher, discussed understanding within the framework of meaning and intention. He argued that understanding occurs when the receiver "recognizes my intention in uttering" whatever was intended to be said (p. 43). Further, he argued that understanding is no more than information acquired, having no effect on the hearer that requires any response. Recognizing intentions, and knowing meaning is fundamental to understanding.

The philosopher, von Wright (1971), examined the concept of "understanding by interpreting." Without meaning as a reference it is difficult, if not impossible, to interpret and therefore understand. To acquire understanding he suggested a linear process via a succession of meaning, intentionality, interpretation and then understanding. In short, there is no understanding without sufficient and timely input from meaning, intentionality, and interpretation.

Facione (1973) pointed out that no one can make another understand. It is up to the receiver to interpret the meaning and intent in order to understand the message. However, there can be a distinction between what a sender intends and what actually can be received. If the sender does not provide accurate, sufficient or required information in a manner the 
receiver can process, there is nothing the receiver can do to understand it. "His speech act has misfired" and he has been unsuccessful in performing the communicative act (p. 283). Intellectually, while the sender is understanding his or her own message, there is failure in getting it across to the receiver. Sender awareness of this often causes the sender to know that he or she is not "being understood."

In the same way a speaker's message may "misfire," a listener's message may not be accurately conveyed. Just as the speaker is responsible for sending accurate, sufficient or required information in a manner the listener can process, so the listener is also responsible for sending the speaker accurate and sufficient feedback simultaneously, as the speaker is speaking. This "cooperative principle" that forms the foundational theory of conversation can be applied to both speaker and listener. Briefly, conversational cooperation is identified by appropriate, sufficient, truthful, and pertinent information that is clear, direct, and organized (Grice, 1975).

To sum, "understanding" is the first level of perceived understanding. Meaning, intention and interpretation are interrelated and are used to evaluate understanding. Actors compare their own perspectives to the perspectives of other actors, to assess their levels of understanding. This first level of perceived understanding deals with the mental state of comprehension. When actors reach a sufficient level of comprehending, understanding may occur, and they may advance to the next level, that of "being understood."

\section{Being Understood}

Laing, Phillipson and Lee (1966) expanded the notion of "understanding" to another level, that of "being understood." Being understood "is the conjunction between the meta-metaperspective of one person and the metaperspective of the other" (p. 29). Plainly speaking, meta-metaperspective is A's view of B's view of A's view of X. When compared to B's view of A's view of X, agreement is required between the perspectives to 
qualify for "being understood." At this level there tends to be agreement between the actors. Laing, Phillipson and Lee (1966) cautioned that some individuals prefer to "understand" rather than "be understood."

An instrument was developed by Cahn and Shulman (1984) to measure perceived understanding, which they define as "the communicator's assessment of his success or failure when attempting to communicate with another person" (p. 122). The instrument uses perception of being understood (PBU) and perception of being misunderstood (PBM) scales. The "being understood" scales range from one to five for each state of: satisfaction, relaxation, pleasure, good, acceptance, comfortableness, happiness, and importance. The same rating system is used for "being misunderstood" states of: annoyance, discomfort, dissatisfaction, insecurity, sadness, failure, incompleteness, and uninterestingness.

Cahn (1983) used the perception of being understood-misunderstood scales, along with three other instruments, to evaluate the importance of understanding in initial stages of interpersonal relationships. Basic communication course students at a midwestern college were randomly paired for 20-minute classroom discussions on future classroom presentation topics of their choice. The 22 males and 38 females were relatively unfamiliar with one another before explaining their topic ideas and listening to responses. The instruments used measured trust, social, and task dimensions of interpersonal attraction, and the perception of being understood. Perceived understanding accounted for only 1 to $1.5 \%$ of the total variance, indicating the irrelevance of being understood-misunderstood when compared to other early relational considerations.

Ideal mateness was the focus of another study (Cahn, 1987b) that used the Perceived Understanding Instrument (Cahn \& Shulman, 1984). The sample numbered 188 men and women recruited from college, community college and adult organizations in upstate New York. Twenty males and 48 females were married, and 35 males and 85 females were single. Results of the data analysis showed that subjects who scored high in 
the perception of being understood tended to see their partners as more ideal mates than those who scored low in the perception of being understood. However, there was less perception of being understood between spouses in married couples than between singles. But among all subjects, those who scored significantly higher in the perception of being understood indicated that their partners were trustworthy, interpersonally attractive, and ideal mates to a much greater degree than those who were low scorers.

Cahn (1989) reported similar research with 155 subjects placed in two categories: a casual dating group and a married/engaged group. In quantifying ideal mateness, the perceived understanding variable showed no significance for the casual group. However, for the married/engaged group the positive correlation was higher between ideal mateness and the perception of being understood than among all other variables measured: intelligence, humor, trust, social attraction, physical attraction, and task attraction.

Broadening the areas of potential research even more, Cahn (1986) proposed the utility of the Perceived Understanding Instrument (Cahn \& Shulman, 1984) in an organizational setting. The intent of the author's call for future research was to expand the area of interpersonal relationship development, specifically between supervisors and subordinates, for the purpose of organizational effectiveness. He argued that perceived understanding is the basis of organizational effectiveness in areas of consideration (person orientation) and initiation of structure (production orientation). Both the areas of consideration and initiation of structure are seen by Cahn as overlapping, when supervisors and subordinates attain mutual perceived understanding.

Further, he noted that organizational effectiveness is influenced by employee satisfaction and job performance which are tied to supervisor-subordinate communication. In addition, he suggested that the role of perceived understanding between supervisors and subordinates be studied because of its positive correlation to interpersonal trust and relationship satisfaction, as well as organizational effectiveness. 
Misunderstood Measure (Shulman \& Fuller, 1981) indicated that patient satisfaction may be preceded by the "feeling of being understood." Therefore, the researcher argued that physicians should be aware of the importance of gaining communication skills that give the patient a "feeling of being understood," if physicians expect to elicit patient satisfaction.

In another study, Cahn (1984) used the Perceived Understanding Instrument (Cahn \& Shulman, 1984) for students' evaluations of their teachers. Near the end of the semester 42 men and 37 women at a northeastern state university participated in evaluations of the instructor conducting the course held just before the basic speech communication class. This provided a broad base of different teachers from various departments, maintaining teacher anonymity.

Of the seven variables measured by five-point Likert scales on the 25 -item questionnaire, perceived understanding was the most potent. According to the measurement scales, the students reporting the "feeling of being understood" correlated positively with the students' positive perceptions of teacher character and expertise. Three specific communication behaviors added to students' perceptions of being understood: teacher classroom/platform behaviors (i.e. use of eye contact, voice, gesture-movement), studentcentered instructional strategies (i.e. listening, showing interest in students), and democratic and participatory teaching style (i.e. high student involvement, effective questioning techniques, informal atmosphere).

In short, acquiring the "feeling of being understood" is more complex than it sounds. Both patients and students reported that the listening behaviors of the doctors or teachers, respectively, were an important factor in their "feeling of being understood." In addition, the students identified contributing nonverbal behaviors, such as eye contact, voice, and movements that their teachers used to give them the "feeling of being understood." 
Using the Perceived Understanding Instrument the concept of the perception of "being understood" has been tested emperically in a number of studies in a variety of settings (Cahn \& Shulman, 1984). This second level of perceived understanding, "being understood," is a cognitive agreement state. When actors reach a sufficient level of cognitive agreement and think they are being understood sufficiently, they may be ready to advance to the next level, where they may experience the "feeling of being understood."

\section{The Feeling of Being Understood}

Laing, Phillipson and Lee (1966) take the two levels of "understanding" and "being understood" to what they consider to be the ultimate level--"the feeling of being understood." They describe the "feeling of being understood" as "the conjunction of one's own direct perspective with one's own meta-metaperspective" (p. 29). To clarify, when A compares A's perception of B's perception of A's view of X to be the same as A's view of $\mathrm{X}, \mathrm{A}$ has "the feeling of being understood." At this level the sender's emotions are the focus, and the sender is "operating between all three levels" (p. 30).

This "feeling" level may be seen by him or her as positive or negative. Laing, Phillipson and Lee (1966) warned that it is not the desired state for all individuals. They asserted that some people actually find it cause for fear because of its potential for closeness with another individual.

Abrams (1989) used an early version (Shulman \& Fuller, 1981) of the Perceived Understanding Instrument (Cahn \& Shulman, 1984) to evaluate satisfaction of physicianpatient interaction. Within a large urban health care organization, the questionnaire was administered to 57 patients in Family Practice and 45 patients in Internal Medicine. "Not listening" was among those physician behaviors listed by subjects as reasons they chose not to return to the same physician. Results from the adapted Feeling Understood- 
The third level of perceived understanding is the "feeling of being understood." The "feeling of being understood" functions as an emotional state that is experienced internally. At the third and final level of perceived understanding, the speaker's "feeling of being understood" influences self-concept, as shown in Figure 1. When actors reach a sufficient level of feeling understood, they are able to function between all three levels.

To sum, Cahn's Theory of Perceived Understanding borrows specific features from Laing, Phillipson and Lee's (1966) Model of Interpersonal Perception, which includes 3 levels of perspectives: 1) direct perspective, 2) metaperspective, and 3) metametaperspective. In addition, when individuals compare the different levels of perspectives, they make judgments regarding their attainment of different levels of perception. Those levels of perception are: 1) understanding, 2) being understood, and 3) feeling understood. Laing, Phillipson and Lee (1966) clearly defined the levels as follows: 1) "understanding" is a mental state of comprehension, 2) "being understood" tends to be a cognitive agreement or acknowledgement state, and 3) "feeling understood" is an emotional state experienced internally.

Within the field of communication, a little more than a decade has been spent publishing, extending, modifying, and explicating "perceived understanding," "being understood," and the "feeling of being understood." Noting the paucity of research results available about the concept of perceived understanding, Cahn's (1985) call for additional applications of the Perceived Understanding Instrument (Cahn \& Shulman, 1984) continues to be applicable today. In his 1985 article, Cahn posited that feeling understood in human interaction is the "meaning of life." Because of this, perceived understanding is ostensibly "an index of practical force subjectively experienced by actors" (p. 192). Therefore, communication scholars were encouraged to investigate perceived understanding as it relates to the constructs of speech acts, self-concept, and development of interpersonal relationships (Cahn, 1985). 


\section{PERCEIVED LISTENING}

It is within that context that this literature review turns now more specifically to an examination of a possible precondition of perceived understanding. In the same way perceived understanding focuses on the speaker's "feeling of being understood," "perceived listening," focuses on the speaker's "feeling of being listened to." The concept of the speaker's "feeling of being listened to" may be a precondition to the speaker's "feeling of being understood."

Cahn and Frey (1989) examined the effects of specific listening feedback behaviors on perceived understanding experienced by the communicator. For the study 72 college students participated from the Midwest and Northeast. Fourteen behavioral impressions of feedback or reaction to communication situations were identified from a content analysis of subjects' open-ended responses. From the responses, a Behavioral Impressions Measure (BIM) was created.

The relationship between behavioral impressions and perceived understanding were then tested by administering the BIM to 245 undergraduates from northeastern, western and midwestern universities. Using 5-point Likert scales and 7-point semantic differential scales, immediately after an assigned interaction, subjects evaluated the use of the 14 behavioral impressions used by a confederate. Then the Perceived Understanding Instrument (Cahn \& Shulman, 1984) was completed by subjects.

Thirteen of the 14 behavioral impressions correlated positively with the total score for perceived understanding. The highest Pearson intercorrelation among the 13 behavioral impressions was $r=.76$. The two impressions were " $X$ paid attention to what you said" and "X did a good job of listening to you" (p. 1301). The other behavioral impressions tested were not as directly related to the listening act itself. Some examples from the BIM are, " $\mathrm{X}$ gave you good advise, helpful suggestions, good ideas," "X was cooperative," and " $X$ was modest, humble." 
Perceived listening may parallel perceived understanding in some ways. The first level of perceived listening may be identified as recognition, mental awareness in the form of recognizing sound. The second level of perceived listening may be identified as acknowledgment. At this level of cognitive agreement the actors acknowledge the listening process by attending to it. The third and final level of perceived listening is internally experienced as an emotion in the form of the "feeling of being listened to," as shown in Figure 1.

\section{The Listener}

Steil, Summerfield and de Mare (1983) argued that the listener's capacity to comprehend is between 400 to 600 words per minute. Witkin (1990) reported listener comprehension to be effective above 375 words per minute. In addition, she argued that listeners increase their attention when listening to faster speaking rates.

Rosenstock-Huessy (1970) recognized the listener as "one-half of the social relation that is established by the process of speech" (p. 135). He also argued that the variety and complexity of the listener's role is equal to such elements within the role of the speaker. While his list of eight listener participation functions is thorough, it stops short of feedback to the speaker. Wolvin and Coakley (1988) argued that listener response was not part of the listening process because listeners who respond are no longer listening to messages, but sending messages.

On the other hand, Rhodes, Watson and Barker (1990) stated that "A competent, or effective listener then, must be able to 'respond appropriately"' (p. 64). Even though listening is perceived as an internal process, the listener must respond in some form to signal the speaker that message processing is or has taken place. Steil, Barker and Watson (1983) also argued that "the response stage of listening is especially critical for judging the success of the listening act as a whole" (p. 22). 
The Steil, Summerfield and de Mare (1983) model (SIER) focuses on four main aspects of listening: sensing, interpreting, evaluating, and responding. It is the responding stage of listening that is necessary "to complete the cycle of communication by indicating in an appropriate way that we have sensed" (p. 12). Further, the authors contended that "nonresponse of any kind" has a negative effect on the speaker-listener relationship, and may, in fact, destroy communication. While they made a convincing argument for "complete attention" during the response phase of listening, they also added to the issue of "nonresponse" by acknowledging the problems resulting from inappropriate responses.

Mills (1974) argued that "You can either hinder or contribute to the success of a communication by the response you make while listening" (p. 37). The listener can demonstrate the desire to understand the speaker's message by responding sincerely with "the eyes and the facial expression," as well as giving "a nod of the head and some slight vocal response" (p. 37). In addition, the author states that a speaker reflecting on a communication experience in which the listener provided the aforementioned responses has the potential for "feeling that complete and satisfactory understanding was achieved" (p. 37).

Rosenfeld (1978) defined the listener in terms of "the total period of time during which the other person is the dominant speaker" (p. 303). He found that during the listening period the listener may display a variety of kinesic responses. In addition, the listener may break silence with brief verbalizations.

\section{LISTENER'S NONVERBAL FEEDBACK BEHAVIORS}

Rosenfeld (1978) discussed the listener's behaviors, referring to them as indicators of the speaker-listener role shift or speaker switching. This function is signaled by the listener's nonverbal cues and short vocal responses. Listeners signal speakers to continue, as well as change speakers. Kendon (1970) speculated that listeners display unique 
nonverbal cues to signal the speaker that the message is being processed. Dittmann (1972a) concurred with Kendon (1970) and added the dimension of listener behaviors as a reaction to the person of the speaker.

Existing research indicates that adults rely more on nonverbal cues than verbal cues when interpreting meaning in social communication situations (Archer \& Akert, 1977; Gitter, Black, \& Fishman, 1975; Haase \& Tepper, 1972; Seay \& Altekruse, 1979; Tepper \& Haase, 1978; Zahn, 1973). Birdwhistell (1955) found that between 60 and 65 percent of social meaning was being communicated nonverbally. Mehrabian and Wiener (1967) reported that only 7 percent of meaning in social interaction was conveyed by the actual words spoken. In addition, they reported that 38 percent of meaning was transmitted through nonverbal vocalics. The remaining 55 percent of meaning is conveyed by the speaker's other nonverbal behaviors.

Approximately 31 percent of meaning is derived from the verbal channel and the remainder of meaning is derived from nonverbal cues, according to the results of a statistical meta-analysis of 23 studies (Philpott, 1983). Similar results were obtained from a pilot study for this thesis, in which forty-four subjects were given questionnaires (see Appendix A) to complete while they waited for airline departures. Responses to the openended questions showed preferences for listener nonverbal feedback to signal the speaker that the listener was listening. Over 90 percent of the pilot study respondents reported a preference for listener eye contact as they spoke. More than half responded with preferences for short vocal responses from listeners, while they were talking. Half of the participants noted a preference for head nods from the listeners while they were speaking. Other responses were limited to 1 or 2 unique answers (see Figure 1). 


\section{Eye Contact}

One nonverbal channel is eye contact, and while it is socially and culturally molded, eye contact appears to be inherent in humans. Spitz (1965) reported that the infant begins eye contact as early as 4 weeks. Confirming Spitz's claim, Caplan (1973) reported that human infants made eye to eye contact at one to three months of age. Other researchers reported that infants engaged in eye contact and fixated on the caregiver's eyes within a few days of birth (Argyle \& Cook, 1976; Roedell \& Slaby, 1977).

Although eye contact appears to be intrinsic and functional at an early age, for decades it went virtually ignored by empirical researchers. Not until 1966 did Psychological Abstracts acknowledge eye contact as a reference. References to eye contact between 1966-1972 only numbered 13 (Kleinke, 1986). As a result, eye contact research is limited in the area of eye contact from the listener, directed at the speaker.

There is a difference between eye contact and eye-gaze. "Eye-gaze is the direction of one's gaze at another's eyes...eye contact defines two people gazing at each other's eyes" (Kleinke, 1986). Among their wide range of classifications of eye behavior, von Cranach and Ellgring (1973) also defined eye contact as the gaze individuals are aware of directing at each other's eyes.

Researchers acknowledge a variety of eye behaviors and other facial behaviors that affect the appearance of eye behavior. For example, Ekman (1985) identified at least eight distinguishable positions of the eyebrows and forehead, eight more of the eyes and lids, and ten for the lower face.

Individuals socialized in the U.S. are more likely to continue eye contact when they feel confident, fluent, and emotionally positive (Brooks, Church \& Fraser, 1986). In addition, eye behavior has been identified with expressions of anxiety, arousal, attitudes, emotions, interaction regulation, and confirming attention (Argyle \& Cook, 1976; Burgoon, Buller \& Woodall, 1989). However, the most important function of eye behavior 
is eye contact, because of its immense potential for sending nonverbal messages (Andersen, 1984). Further emphasizing the importance of eye contact in U.S. culture, McCaskey (1978) asserted that "...a person shows he is listening, providing deference or encouragement to a speaker, by looking at the speaker. A listener who does not look at a speaker is often taken to be inattentive" (p. 71).

\section{$\underline{\text { Vocalics }}$}

Paralinguistics or vocalics is another important aspect of nonverbal behavior, which originates with the human voice (Andersen, 1984). Vocalics is the preferred term and includes all vocally audible behavior, except spoken words (Burgoon, Buller \& Woodall, 1989). According to Andersen and Bowman (1985), vocalics include the vocal qualities of pitch, tempo, rhythm, and resonance. They also include in their definition, vocal segregates like "ah", "uhuh," and "um" as components of vocalics. Other important elements of vocalics are vocal characterizers such as laughing, yawning, and crying.

Like eye contact, while vocalics are socially and culturally molded, they appear to be inherent in humans. Harris and Rubenstein (1975) asserted that infants appeared to attend to vocalic cues from birth. Other researchers also reported that infants were capable of vocalization at birth (Menyuk, 1971, 1972; Wood, 1981). In addition, Roberts (1987) reported that parents could distinguish their infants' prebabbling ability by the changing tones of the crying vocalizations that the infants use to indicate their immediate needs. Then, between three and six months of age the infants enter the babbling period and crying is replaced by speech sounds. Although babbling sounds initially extend beyond the infant's own language, because parents tend to reward the infant for vocalic cues consistent with their own language, the other vocalizations become less frequent (Menyuk, 1971, 1972; Wood, 1981). 
Burgoon, Buller and Woodall (1989) stated that "vocalic cues are among the most powerful in the nonverbal repertoire," rivaling kinesics (p. 63). Researchers have reported that subjects who hear content-free vocalic utterances are able consistently to identify the types and intensities of the emotions being expressed (Starkweather, 1961; Scherer, Koiwunaki \& Rosenthal, 1972). As referred to earlier, Mehrabian and Wiener (1967) reported that as much as 38 percent of social meaning is derived from vocalics. Vocalic responses from the listener may be as simple as an acknowledgment of the speaker's utterance (Rosenfeld, 1966; Snyder, 1945). Rosenfeld (1978) argued that the "mm-hmm" is commonly considered functionally equivalent to the silent head nod as a signal not to change speaker-listener roles.

\section{$\underline{\text { Head Nods }}$}

In addition to eye contact and vocalics, head nods are an important form of nonverbal feedback. Unlike eye contact and vocalics, the head nod does not appear to be inherent in infants, but is socially developed. For example, Dittmann (1972b) studied children in grades 1,3 , and 5 and reported that their listener head nod response was nearly absent, unless the other communication partner placed a strong demand on the child to nod. However, when the adolescent's peers lengthened their verbal responses, the eighth graders studied had more opportunity to display head nods.

In 1978, Rosenfeld argued that a consensus was emerging that placed the head nod among those kinesic responses most widely used by listeners. One of the functions of the head nod is as a regulator. For example, Rosenfeld (1978) interpreted a head nod from the listener as a possible signal to the speaker that the listener is deferring speaking time and encourage the speaker to continue.

Prior to Rosenfeld's observation, Birdwhistell (1970) produced a work that detailed the variations in head nods. He presented "five kinesic stem-forms" from which nods 
emerge (p. 163). The different types of head nods perform different functions. For instance, the common nod signifies agreement or encouragement. However, in the extreme of nods, the "understanding nod" is over-used. A specific example was found in the case of medical school residents "often beating time to the pulse of their own anxiety rather than to the rhythm of the patient's story" (Birdwhistell, 1970, p. 162).

The "stem-forms" of head nods are influenced by "motion qualifiers" (Birdwhistell, 1970, p. 164). The categories include intensity, range, and velocity. Intensity originates in the neck muscles and the five levels of intensities vary from overtense to lax. Range describes the amount or scope of movement, from narrow to broad. The velocity or duration of a nod goes from "staccato, N, and allegro" (p. 165). Even though it is possible to have many variations of head nods, because the movement takes place in a centralized area of the body, various types of head nods interchange satisfactorily. While Birdwhistell found the variations in head nod behavior kinesically insignificant, he argued that head nods were significant in the communication experience.

Finally, an extensive review of the literature in a variety of fields has revealed limited experimental research focusing on listener nonverbal feedback behaviors that contribute to the speaker's "feeling of being listened to." Nor does the literature or research sufficiently address the concept of the relationship between the "feeling of being listened to" and the "feeling of being understood." Because the "feeling of being understood" and the "feeling of being listened to" both contribute to the development of a positive selfconcept, research from a communication perspective is needed in the areas of perceived understanding, perceived listening and the influence of eye contact, vocalics, and head nods. Therefore, the following hypotheses are posed:

H1 The listener's use of eye contact will be positively associated with the speaker's feeling of being listened to. 
$\mathrm{H}_{2}$ The listener's use of vocalics will be positively associated with the speaker's feeling of being listened to.

$\mathrm{H}_{3}$ The listener's use of head nods will be positively associated with the speaker's feeling of being listened to.

Eye contact, vocalics, and head nods are each independent in their effects as nonverbal feedback behaviors. They are also additive in nature.

$\mathrm{H}_{4}$ The listener's use of eye contact, vocalics, and head nods will be positively associated with the speaker's feeling of being listened to.

$\mathrm{H}_{5}$ The speaker's feeling of being listened to will be positively associated with the speaker's feeling of being understood.

The method and procedure used to test these hypotheses is discussed in the following chapter. 


\section{CHAPTER III}

\section{METHOD AND PROCEDURE}

\section{INTRODUCTION}

This chapter describes the methods and procedures used in this study. Method, the first section, discusses the design, the participants, and the measurement instruments. The second section, Procedure, discusses recruitment and process.

\section{METHOD}

\section{Design}

One-hundred eight subjects were randomly assigned to view one of twenty twoand-a-half-minute videotapes of a person functioning as a listener. The visible listener was listening to a story being told by an off-camera voice. The listener manipulated his or her nonverbal behaviors in accordance with the specific condition being measured. The story told by the audio-taped speakers, as well as their nonverbal feedback behaviors, was thoroughly tested and reviewed by both educators and students, and found to achieve the research goals. The nonverbal variables manipulated by the listening researcher were eye contact, vocalics, and head nods. In addition, the sex of the speaker was also a manipulated variable.

Twenty-one subjects viewed tapes in which the listener responded to the story-teller with all three nonverbal categories (see Table I). At the other end of the spectrum 21 subjects were deprived of witnessing the three nonverbal variables. Twenty-one subjects were exposed to listener behavior limited to eye contact. Brief vocal responses from the 


\section{TABLE I}

\section{SUBJECT DISTRIBUTION BETWEEN LISTENER'S NONVERBAL BEHAVIORS}

Female Listener

No: Eye Contact, Vocalics, and Head Nods

Eye Contact

Vocalics

Head Nods

Eye Contact, Vocalics, and Head Nods

\section{Male}

Listener

No: Eye Contact, Vocalics, and Head Nods

Eye Contact

Vocalics

Head Nods

Eye Contact, Vocalics, and Head Nods
Female

Speaker

7

7

7

7

8

2

4

5

5
Male
Speaker

4

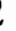

6

4

$7 \quad 3$

$7 \quad 3$

$7 \quad 4$

$8 \quad 3$


listener were the only feedback behaviors observed by another 22 subjects. Twenty-three subjects viewed videotapes in which the listener responded with head nods only.

Each subject viewed a videotape with a sound track that matched the subject's own sex. In other words, all women heard the same woman tell the story and all men heard the same man tell the identical story. Both men and women subjects were randomly assigned to view videotapes of same-sex or opposite-sex listeners who responded to the story.

\section{Participants}

One-hundred eight students enrolled at Portland State University were randomly assigned to the various conditions. They came from a pool of volunteers solicited through classes in introductory history, introductory psychology, introductory speech communication, mathematics, English, and economics, in order to provide a varied population mix (see Table II). Some instructors gave their students extra credit for their participation in the research.

\section{Measurement Instruments}

Two separate instruments, with a total of three scales, were used to measure participants' responses to the variables. After viewing a videotape by random assignment, each participant was given two questionnaires to complete. Each participant completed the Perceived Listening Questionnaire (Appendix B), followed by Cahn and Shulman's (1984) Perceived Understanding Instrument (see Appendix C).

The Perceived Listening Questionnaire contains two scales, the listening scale and the understanding scale. The listening scale contains six questions, and measures the speaker's "feeling of being listened to." The understanding scale contains five questions, and measures the speaker's "feeling of being understood." The questionnaire consists of 20 questions, measuring listening and understanding. The questions are randomly ordered, including questions pertinent to the cover story that this research was a study of 
TABLE II

SUBJECT INFORMATION BY MAJOR, CULTURAL BACKGROUND, AGE, AND GENDER

\begin{tabular}{|c|c|}
\hline Academic Major & $\underline{\text { Subjects }}$ \\
\hline Science & 20 \\
\hline Humanities & 9 \\
\hline Fine Arts & 1 \\
\hline Behavioral Science & 7 \\
\hline Business & 18 \\
\hline Computer/Engineering & 7 \\
\hline Social Science & 16 \\
\hline Education & 15 \\
\hline Speech Communication & 4 \\
\hline Undecided & 11 \\
\hline \multicolumn{2}{|l|}{ Cultural Background } \\
\hline Asian & 17 \\
\hline Black & 5 \\
\hline European & 47 \\
\hline Hispanic & 9 \\
\hline Mediterranean & 0 \\
\hline Other & 30 \\
\hline \multicolumn{2}{|l|}{ Age } \\
\hline Under 20 & 26 \\
\hline $20-24$ & 50 \\
\hline $25-29$ & 13 \\
\hline 30-39 & 14 \\
\hline $40-50$ & 5 \\
\hline Over 50 & 0 \\
\hline \multicolumn{2}{|l|}{$\underline{\text { Gender }}$} \\
\hline Female & 68 \\
\hline Male & 40 \\
\hline
\end{tabular}


storytelling. The questionnaire uses a 5-point Likert-type scale ranging from (1) strongly disagree to (5) strongly agree.

The Perceived Listening Questionnaire was developed for this research by using subject responses from a pilot study conducted by this researcher. In the pilot study, fortyfour subjects were each given a questionnaire (see Appendix A) to complete while they waited for airline departures from John Wayne International Airport in Orange County, California. Subjects responded to two open-ended questions about their listening behaviors and two open-ended questions about the listening behaviors of those to whom they spoke. Responses to the four open-ended questions were grouped into categories. Three categories clearly emerged: eye contact, vocalics, and head nods. The Perceived Listening Questionnaire was designed to measure the three attending behaviors that were associated with the feeling of being listened to (see Table III). In addition, the understanding scale measures the feeling of being understood (see Table IV), and was included to test the convergent validity of the Cahn and Shulman (1984) instrument, which uses single words rather than complete sentences.

The Perceived Understanding Instrument (Cahn \& Shulman, 1984) comprises 24 items. Every third item is a word that measures either "understanding" (see Table V), "misunderstanding" (see Table VI) or is a distracting word. The instrument was constructed from open-ended responses to questions of how individuals felt when they were understood or misunderstood. After a Q-sort by Cahn and Shulman the instrument was constructed, tested and retested. After a test-retest, the researchers obtained a Cronbach alpha of .89 for their instrument, indicating that the scale is reliable. The Perceived Understanding Instrument uses a 5-point Likert-type scale ranging from (1) strongly disagree to (5) strongly agree. 
TABLE III PERCEIVED LISTENING ITEMS

1. I felt that the listener was really listening.

2. The listener made a conscious effort to hear the story.

3. The listener paid close attention to the story.

4. The listener was not a good listener.*

5. The listener should have been listening better.*

6. The listener gave undivided attention to me.

* These items were reverse coded. 


\section{TABLE IV}

\section{LISTENING UNDERSTANDING ITEMS}

1. I felt uncomfortable because of the listener.*

2. I felt comfortable with the listener.

3. The listener really understood me.

4. The listener did not understand me.*

5. The listener made me feel like I was understood.

* These items were reverse coded. 


\author{
TABLE V \\ PERCEIVED UNDERSTANDING INSTRUMENT \\ UNDERSTANDING ITEMS \\ Satisfaction \\ Relaxation \\ Pleasure \\ Good \\ Acceptance \\ Comfortableness \\ Happiness \\ Importance
}


TABLE VI

\title{
PERCEIVED UNDERSTANDING INSTRUMENT MISUNDERSTANDING ITEMS
}

\author{
Annoyance \\ Discomfort \\ Dissatisfaction \\ Insecurity \\ Sadness \\ Failure \\ Incompleteness \\ Uninterestingness \\ * All of these items were reverse coded.
}




\section{PROCEDURE}

\section{$\underline{\text { Recruitment }}$}

After the Human Subjects Research Review Committee reviewed and approved the proposed research project, subjects were recruited for a study of storytelling. Subjects were told that they would view a 3-minute videotape of an individual telling a story. They would then be asked to complete two questionnaires. The entire process was expected to take approximately 12-minutes. Subjects were also told that their responses would remain anonymous and confidential, for the use of the researcher only.

\section{Process}

When a subject arrived, the researcher asked him or her to play an audio-cassette explaining the research procedure in detail. Each participant was alone in a small conference room, seated at a table, while listening to the audio-taped instructions, and viewing the videotape. Subjects were given a script of the instruction tape (see Appendix D). Inserted between the appropriate pages of the instruction script were the Informed Consent Form (see Appendix E) to sign and the Information Sheet (see Appendix F) with demographic information to circle. Included in the instruction script was a copy of the story (see Appendix G) that the subject would imagine himself or herself to be speaking as he or she viewed the videotape later. The participants were told that they had control of the off-on buttons and could adjust the sound as required. Three participants stopped the audio-taped instruction cassette to leave the room and ask the researcher a question for clarification.

When the subject notified the researcher that he or she was ready, the researcher started the videotape and again left the subject alone in the room. None of the participants stopped the videotape before it was completely over. When the subject finished viewing the 
videotape, the subject was given two questionnaires to complete (see Appendix B \& C). Participants were verbally thanked by the researcher and given a thank-you note. The results of testing the hypotheses are discussed in the following chapter. 


\section{CHAPTER IV}

\section{RESULTS}

\section{INTRODUCTION}

This chapter describes the manipulation check and testing of the listening scale, the understanding scale, and the perceived understanding scale (Cahn \& Shulman, 1984). In addition, a report is given of the results of the tests of the research hypotheses and post-hoc analyses.

\section{MANIPULATION CHECK}

If the videotaped manipulations of nonverbal feedback behaviors worked, expected

- results would be that: 1) each individual nonverbal feedback behavior is independently associated with the speaker's feeling of being listened to, 2) when used during the same communication experience, all three nonverbal feedback behaviors are additive when associated with the speaker's feeling of being listened to, and 3) the feeling of being listened to is associated with the feeling of being understood.

A manipulation check was conducted to test the reliability of the conditions being depicted and measured by viewing the videotapes. Twenty-five men and 36 women from two introductory psychology classes and one introductory speech communication class volunteered to view five randomly-selected videotapes, one from each condition. All students were given extra credit points in their respective classes for their participation. Each group of four to ten volunteers were randomly assigned to a different ordering of the randomly selected videotapes. Each group saw all five videotapes during one session, lasting about 17 minutes. A questionnaire (see Appendix H) was completed by each 
volunteer at the conclusion of each tape. Each individual was asked to rate the listener's nonverbal responses to the speaker by using a scale of 0 to 10 , with 10 being the highest and 0 being the lowest. Data analysis showed that all conditions were accurately portrayed (see Table VII).

\section{SCALES}

Cronbach's alpha equals .87 for the listening scale. The understanding scale alpha equals .80. An alpha of .88 was obtained for the perceived understanding scale (Cahn \& Shulman, 1984).

\section{RESEARCH HYPOTHESES TESTS}

The results of testing Research Hypotheses One through Four are shown in Tables VIII and IX. The scales were tested by using ANOVA. Because there is no significant effect for any of the four hypotheses, no post hoc analyses were performed.

The testing of Hypothesis Five yielded a correlation of $r=.53(p<.05)$. This result shows a significant correlation between the speaker's "feeling of being listened to" and the speaker's "feeling of being understood." While the available literature and logic indicate a positive relationship between nonverbal feedback and the speaker's "feeling of being listened to," analysis of this study's data shows no correlation between the speaker's "feeling of being listened to" and nonverbal feedback behaviors. However, since the feeling states of listening and understanding are significantly correlated, if the "feeling of being listened to" is not significantly effected by the listener's nonverbal feedback behaviors, perhaps the "feeling of being understood" is not significantly effected by the listener's nonverbal feedback behaviors. With this in mind, a post hoc analysis was performed to measure the correlation between the speaker's "feeling of being understood," and nonverbal feedback behaviors. 


\section{TABLE VII}

\section{MANIPULATION CHECK MEANS AND MEDIANS FOR EYE CONTACT, VOCALICS, AND HEAD NODS, BY CONDITION}

$\begin{array}{llcc} & \text { Eye Contact } & \text { Vocalics } & \text { Head Nods } \\ \text { Condition } & \text { Mean Median } & \text { Mean Median } & \text { Mean Median }\end{array}$

No: Eye Contact,

Vocalics, and

1.20

.10

.20

Head Nods

Eye Contact

6.37

$0 \quad 0$

.50

Vocalics

3.42

$\begin{array}{ll}6.6 & 7\end{array}$

1.50

Head Nods

4.24

.10

$\begin{array}{ll}7.8 & 8\end{array}$

Eye Contact,

Vocalics, and

$\begin{array}{ll}7.9 & 8\end{array}$

7.6

8

$8.2 \quad 9$

Head Nods 
TABLE VIII

ANALYSIS OF VARIANCE: FIVE NONVERBAL CONDITIONS FOR PERCEIVED LISTENING

$\begin{array}{lccccc}\text { Source } & \underline{\mathrm{DF}} & \underline{\mathrm{SS}} & \underline{\mathrm{MS}} & \underline{\mathrm{F}} & \underline{\mathrm{P}} \\ \text { Between Groups } & 4 & 260.40 & 65.10 & 1.63 & .17 \\ \text { Within Groups } & 103 & 4126.52 & 40.06 & & \\ \text { Total } & 107 & 4386.92 & & & \end{array}$


TABLE IX

MEANS AND CELL SIZE OF FIVE NONVERBAL CONDITIONS FOR PERCEIVED LISTENING

Condition

No: Eye Contact, Vocalics, and Head Nods

Eye Contact

Vocalics

Head Nods

Eye Contact, Vocalics, and Head Nods

$* * F(4,107)=.178$ n.s.

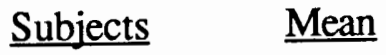

$21 \quad 16.34$

21

14.34

22

13.82

23

18.04

21

16.38 


\section{POST HOC ANALYSIS}

The model in Figure 1 was developed from an integration and extension of existing theory, this researcher's pilot study, and logic. As depicted in Figure 1, nonverbal feedback behavior should have been positively correlated with the speaker's "feeling of being listened to," but did not. According to the same figure, nonverbal feedback behavior should be positively correlated to the speaker's "feeling of being understood." Since the "feeling of being listened to" and the "feeling of being understood" were positively correlated, a post hoc analysis was done to determine the probability of the "feeling of being understood" and nonverbal feedback behavior positively correlating as the model indicates. However, results of the post hoc analysis shows that there is no significant correlation between the "feeling of being understood" and nonverbal feedback behavior. The results are reported in Tables $\mathrm{X}$ and XI.

As indicated by the analyses of the research data, the associations between nonverbal feedback and the speaker's feelings of being listened to or understood were too weak in this situation to yield any significant results. The implications of these findings will be discussed in the following chapter. 
TABLE $\mathrm{X}$

\begin{tabular}{lccccc}
\multicolumn{6}{c}{ ANALYSIS OF VARIANCE: FIVE NONVERBAL } \\
CONDITIONS FOR PERCEIVED & UNDERSTANDING \\
Source & $\underline{\text { DF }}$ & $\underline{\text { SS }}$ & $\underline{\text { MS }}$ & $\underline{\text { F }}$ & $\underline{\mathrm{P}}$ \\
Between Groups & 4 & 102.48 & 25.62 & 1.37 & .25 \\
Within Groups & 103 & 1931.82 & 18.76 & & \\
Total & 107 & 2034.30 & & &
\end{tabular}




\section{TABLE XI}

MEANS AND CELL SIZE OF FIVE NONVERBAL CONDITIONS FOR PERCEIVED UNDERSTANDING

Condition

No: Eye Contact, Vocalics, and Head Nods

Eye Contact

Vocalics

Head Nods

23

47.83

Eye Contact, Vocalics, and Head Nods

21 46.24

** $F(4,107)=.178$ n.s. 


\section{CHAPTER V \\ DISCUSSION AND CONCLUSIONS}

INTRODUCTION

This final chapter discusses implications of the findings, the study limitations, and conclusions and suggestions for future research.

\section{DISCUSSION}

Implications of the Findings

The focus of this study was two-fold. The first and primary focus was to examine the significance of eye contact, head nods, and vocalics as listener behaviors that affect the speaker's "feeling of being listened to." The secondary focus was to examine the significance of the speaker's "feeling of being listened to" as it relates to the speaker's "feeling of being understood."

With these foci in mind, the purpose of this study was to test five hypotheses formulated as a result of studying this researcher's model (see Figure 1), this researcher's pilot study, and logic. The first four hypotheses tested the importance of eye contact, vocalics, and head nods as listener behaviors that affect the speaker's "feeling of being listened to." There was no significant relationship between the nonverbal feedback behaviors and the "feeling of being listened to." That is, this study found no evidence to support the claim that the three listener nonverbal feedback behaviors of eye contact, vocalics or head nods alone or together are important to the speaker's perception of the "feeling of being listened to." In light of the available literature and this researcher's pilot study, the lack of support for the first four hypotheses is surprising. 
Hypothesis Five examined the correlation between the states of the "feeling of being listened to" and the "feeling of being understood." Initial analysis of the model (Figure 1) revealed a significant correlation between the two feeling states. When being measured, the "feeling of being listened to" and the "feeling of being understood" are indistinguishable or may even be the same concept. Therefore, it may be reasonable to expect that both the "feeling of being listened to" and the "feeling of being understood" are affected by the same behaviors. In fact, results from a post-hoc analysis show similar results for both feeling states when they are measured by the listener's nonverbal feedback behaviors of eye contact, vocalics, and head nods. Simply put, eye contact, vocalics, and head nods from the listener failed to have a significant effect on either the speaker's "feeling of being listened to" or the speaker's "feeling of being understood."

The model in Figure 1 is an integration and theoretical extension of the relevant literature, this researcher's pilot study, and logic. According to the model, the specific listener nonverbal feedback behaviors being tested should have been significantly correlated with each of the feeling states in the model. It was theorized that since self-concept is influenced by the speaker's feelings of being perceived, listened to, and understood, each of the feeling states are theoretically influenced by the nonverbal feedback behaviors of eye contact, head nods, and vocalics.

However, the nonverbal feedback behaviors are not related to either feeling state. According to the findings in this study, nonverbal behavior does not appear to matter in actuality to the degree suggested by the literature, this researcher's pilot study, and logic. In light of this study's limitations, this researcher must guardedly question the validity of past experimental research results that report such correlations. The validity of experimental research will be discussed further in the section on study limitations which begins after the following discussion of why this study may have resulted in these unexpected findings. 
The discussion includes possible limitations caused by threats to internal validity and threats to external validity.

\section{STUDY LIMITATIONS}

\section{Threats to Internal Validity}

Possible explanations for the non-significant results may include aspects of this study's internal limitations, the limitations of research generalizations, and undetected flaws in previous research. In light of the findings, several internal limitations in the study itself must be examined.

First, it may be argued that in this study no attempt was made to determine the individual's visual ability or to monitor the individual's visual attention while viewing the videotape. After thorough instructions, it was assumed that subjects were not visually impaired and that they would visually attend to the two-and-a-half-minute videotape. In addition, provision was made to remove all possible external distractions, which appeared to be successful.

However, while external distractions were controlled, there may have been the opportunity for partial or complete interference with the evaluating task if the subject felt stressed. Keeley-Dyreson, Burgoon and Bailey (1991) argued that individuals experiencing stress have the potential to inaccurately decode the communication of others. Admittedly, no control was in place to evaluate or eliminate the level of stress experienced by the participants. Therefore, if individuals participating in this study were undergoing stress, this may have reduced the subjects' ability to accurately decode and evaluate the listener's responses. Yet, this researcher believes that the number of such participants should not have varied significantly from participants similarly stressed in previous studies of nonverbal feedback behaviors. 
Another study limitation may have been the use of a VCR and a videotape, which could have created a lightly artificial environment for the subject. However, while the study participants were not polled as to their familiarity with VCRs and videotapes, because of the prevalent presence of such technology in U.S. society, it is likely that these students were in fact familiar with these tools and this research was not adversely influenced by them in a general way, at a general level. However, the videotape and monitor may have been too artificial an environment for the subjects to place themselves vicariously in the imaginary situation of being the speaker. For example, Ekman and Friesen (1967) reported that observers' judgements of perceived nonverbal cues was without subjective emotional involvement because of the lack of immediacy in the videotaped interaction.

In addition, there was no control for perspective-taking ability by subjects. Each subject was thoroughly instructed in the procedure for taking the speaker's perspective, but may have had varied levels of success in fulfilling that objective. There was a need for the subjects to be high in perspective-taking ability for the simulation to work.

Chovil (1991) pointed to a low social situation being defined as having no person present, such as a videotape. When the subject sees him- or herself as a viewer rather than an interactor, eye contact, head nods, and vocalics from the videotaped listener did not matter as much as they would have mattered in actual face-to-face immediacy. In the videotaped situation, it is argued, the subjects (imagining him- or herself to be the speaker) were unable to participate verbally or nonverbally, matching the speaker's behavior. For example, a subject may have thought on some level, "I can't respond nonverbally, so it's not important that you don't." Therefore, constructing a research environment devoid of the physical presence of another individual may have thwarted actual subject participation.

Chovil and Fridlund (1991) asserted that the listener's face is as referential as any words because one person is providing messages to another. In this study, the speaker- 
subjects were viewing the three-quarter to full faces of the listeners. But no spontaneous reactions were possible between the speaker-subjects and videotaped listeners.

In short, consideration must be given to the difference between this popular video environment and actual face-to-face human interaction. This study was designed to replicate actual face-to-face simulations between peers, in a social environment. The replication of actual face-to-face simulations between peers was accomplished by design, but the human element of immediacy was sacrificed for the purpose of obtaining results based upon consistent presentations of the manipulations. While it was the best possible combination of simulation and control, it was limited because it was a contrived situation.

Further, some may argue that the medium is not the limitation, but the content. However, the story told by the audio-taped speakers was thoroughly tested and reviewed by both educators and students to detect any flaws or possible barriers to achieving the research goals. The story was repeatedly found to be effective by all reviewers who gave their responses, some prior to any knowledge of the research project and others with full knowledge of the project's goals.

Because the field of listening is still in its infancy, it is difficult to find comparable studies to use in the discussion of limitations, but there are comparable studies in other areas of nonverbal communication. One example of the limitations of research generalizations is found in Argyle (1970), in which he reported that eye contact is only one process among many that are taking place in dyadic interaction. Admittedly, so, too, is the cluster of eye contact, head nods, and vocalics only one set of one of the processes that are taking place among many in the listening process, thus making generalizations more difficult.

It is interesting to note that a cross section of the student population in this study did not find nonverbal feedback behavior from an unknown listener to be as important as the literature suggested or the pilot study led us to believe. However, these nonverbal listener 
feedback behaviors may be important for a particular sex, culture, or type of relationship. The level of importance for listener nonverbal feedback may be unique to each individual's biological make up, cultural socialization, and individual experiences, which give each of us our needs and preferences.

It should also be acknowledged that there was no control for cultural variation in nonverbal communication norms. Gudykunst and Kim (1984) pointed out that "many white North Americans break an action readily if they do not like the way things are going or if something or someone better comes along" (p. 155). The action referred to can be any form of nonverbal behavior between two individuals. The authors also pointed out that "This can be very frustrating to a stranger from a high-context culture emphasizing completion of action chains in interpersonal relationships" (pp. 155-6). This study did not control for the level of cultural context preferences and variations.

Another possible explanation for the non-significant results in this study may be undetected flaws, misleading results, or misinterpretations of previous studies. If the literature is correct and the design valid, significant results for nonverbal listener feedback behaviors and the feeling states should have been obtained in this study. In other instances, undetected flaws in research have been found after the fact, and because of the undetected flaws, misinterpretations have also occurred.

In one such instance, Stephenson and Rutter (1970) argued that the eye contact research by Argyle and Dean (1965) produced results that could be accounted for by observer errors. In a rebuttal by Argyle (1970), he acknowledged methodological questions of contrived laboratory experiments. In addition, Argyle addressed eye contact as only one process and the inability to isolate one physical behavior from all others taking place simultaneously.

Another example of undetected flaws resulting in misinterpretations may be found in Buck's (1991) accusation of manipulation of stimuli strength which altered the 
experience and expression of facial displays reported by Chovil (1991) and other investigators. He proposed that their results had been misinterpreted and should be reinterpreted as demonstrating social motivational/emotional systems that are not emotionally independent displays of human expressiveness, but are found to be in addition to the primary affects controlling such displays. Chovil and Fridlund (1991) concluded their response to Buck's accusation with the admission that they were raising issues and unanswered questions while, at the same time, offering an alternative perspective accounting for the variety of observed facial displays.

In addition, Ekman (1965) admited specific problems with his research, after the fact. But how many researchers do not admit or even see the problems with their research, let alone limit generalizations as Ekman cautioned? Among his reasons for caution in limiting the generality of research results was "Nonverbal behavior was sampled from a single situation" (p. 732).

However, Smith, Archer and Costanzo (1991) reported that perceivers do seem to be aware of nonverbal cues and their significance in interpreting behavior. Multiple, redundant, important nonverbal cues are "diffused" throughout interactions, and perceivers who cite different cues as important may be correct, as are their fellow perceivers who cite "other" cues as being important. In other words, while there may always be methodological problems possible in nonverbal research, there may also be innocent and accurate variations among perceivers, as well as confounding variables not measured.

\section{Threats to External Validity}

Attribution and Inference. Research indicates that individuals perceive others based on the ways in which they perceive themselves (Feldstein \& Bond, 1982). Therefore, if the speaker thinks he or she fulfills his or her speaking role, the speaker thinks the listener fulfills his or her listening role. It may not actually be the stimuli of positive nonverbal 
feedback from the listener that makes the speaker feel that his or her communication partner is listening. It may be the speaker's perception of the way he or she fulfills his or her speaking role that convinces the speaker that the listener is listening, regardless of the external stimuli--unless something is exceptionally or obviously wrong. This "I speak. Therefore, you listen" attitude may also be viewed as a faulty assumption on the part of speakers (Adler \& Towne, 1990).

Attribution theory's three basic assumptions are: 1) Individuals try to ascertain the reason(s) for particular behavior(s) of others, 2) Individuals ascribe reasons systematically to the behavior(s) of others, and 3) The perceived ascribed reason(s) affect the perceiving individual's own feelings and behaviors. In an effort to resolve the ambiguities of communication, "In most cases we cognize a person's traits, and especially his wishes, sentiments, or intentions from what he does and says...." (Heider, 1958, p. 39).

In the case of a single observation, such as was actually presented to subjects (perceiving individuals) in this study, attribution theory's "discounting effect" may present an explanation for the research results. Subjects may have weighed the possible causes of the listener nonverbal feedback behaviors, or their absence, in relation to other factors and generalized the effect of listening based on the available data. In other words, "The role of a given cause in producing a given effect is discounted if other plausible causes are also present" (Kelley, 1973, p. 108).

In addition, Ross (1977) emphasized the need to avoid underestimating the impact that the environment or situation may have on an individual's behavior. While individual's may account for the behaviors of others by attributing causal factors to the actor's internal make-up or motivation, it is necessary to acknowledge actors' responses to external environmental and situational factors. Therefore, it is possible that speaker-subjects in this study were attributing listening behavior to the videotaped listener merely because the speaker-subject interpreted the occasion as a listening situation. 
Along the same lines, Stephenson and Rutter (1970) asserted that people (observers) want eye contact or expect eye contact, so they see or interpret eye contact whenever it is a possibility. Using this type of logic, speakers interpret listening behavior as fulfilling and satisfying speaker needs to "feel" listened to whenever it is possible to interpret it as so, whether it is actually present or not. Because the speaker expects his or her communication partner to be listening and is interpreting the listener's behaviors as affirmations of attention, the listener's attention may be questioned only during obvious incongruity in regard to the expected behavior of the listener role.

Another possible explanation for the research results may be found in the concept of inference. "It is likely that the most important part of our communication is the part we infer. And yet we do this through our screen of personal biases, our needs, and our affective states" (Weaver, C. H., 1972, p. 70). In addition, Sperber and Wilson (1986) pointed out that, "No one has any clear idea how inference might operate over nonpropositional objects: say, over images, impressions or emotions" (p. 57). Subjects in this study may not have been able to separate their own personal meanings or interpretations from the speaker-subject task. Drawing subjective, biased inferences based on their own needs may have caused the speaker-subjects to draw their own personal inferences about listener nonverbal feedback behaviors that could have been subject to error, moreso than if the subjects used unbiased reason, logic, and fairness instead of opinions, feelings, and biases. However, this study was intended to test feeling states, and the results may, in fact, reveal the inaccurate inferences relating to images, impressions or emotions that subjective individuals make during their normal communication interactions.

Relevance. According to Pearson and Nelson (1988), in order for information to be relevant to an individual, the individual must be able to make a connection between the information and the individual's experience. Communicators initially assume relevance when they give attention to a message. "The principle of relevance applies without 
exception: every act of ostensive communication communicates a presumption of relevance" (Sperber \& Wilson, 1986, p. 162). However, an individual's initial assumption of relevance may be either confirmed as being relevant enough or else be evaluated as not being relevant enough. Speaker-subjects in this study may have found insufficient relevance in the content of the story being told, the listener feedback behaviors, or the research situation itself.

In addition, the degree of relevance an individual assesses is also determined by the individual's own level of intellectual alertness and "ability to infer the communicator's intentions" (Sperber \& Wilson, 1986, p. 165). If the speaker-subjects were not on a level of intellectual alertness in performing the research task, the results of this study would be negatively affected. In much the same way, if the speaker-subjects possessed the ability to infer the communicator's (listener's) intentions, and did so, then the results of this study would also be affected.

Relevance is also determined by the effort involved in accessing it. "An assumption is relevant to an individual to the extent that the effort required to process it optimally is small" (Sperber \& Wilson, 1986, p. 145). In addition, the authors also asserted that the individual needs to quickly make a connection of importance to the self. Therefore, results of this study could have been affected by speaker-subjects who did not make a quick, easy, and personal connection with their speaker role.

Ritchie (1991) pointed out that a change in context during a communication interaction may cause an individual to alter his or her interpretation of previous parts of the communication. Further, when the context is altered the relevance is also altered. Since subjects in this study were recruited to help research storytelling, the speaker-subjects' focus of relevance may have been on the story during the videotape process. Then, when speaker-subjects were completing their questionnaires that included questions about listener 
nonverbal feedback behaviors, they may have altered the relevance of the videotape experience to reflect what they presumed was suppose to be relevant, after the fact.

"Data may have more or less relevance, but events must be at the very least relevant to some communicative interaction to be accepted as data" (Ritchie, 1991, 20). It may be that speaker-subjects in this study were unable to associate the videotaped event as a relevant communicative interaction, thus making it difficult for the speaker-subjects to accurately evaluate the importance of the listener nonverbal feedback behaviors that they had observed.

Similarly, the internal, emotional relevance between the speaker-subjects and videotaped listeners may have affected the results of this study. Berger and Calabrese (1975) reported that nonverbal behavior in the form of eye contact and head nods is more frequent per minute between individuals who like each other than persons who dislike each other. Since the subjects in this study did not know the videotaped listeners they were observing, the frequency of nonverbal feedback behaviors may not have been as important and expected as it would have been if the speaker-subjects were observing listeners they liked.

Other Threats. Buck (1991) discussed the presence of others to inhibit or elicit responses. For example, an individual's expectations create a situation in which a particular level of nonverbal feedback becomes a necessary part in communication. But when an individual is alone (as subjects were in this study), nonverbals are not as essential. In other words, nonverbal feedback requirements are not static, but fluctuate according to an individual's immediate needs. Therefore, if a passive communication partner will let an individual talk, the speaker may be satisfied. But when the communication partner responds with noticeable appropriate nonverbal feedback, the speaker may feel really great! This suggests that speaking may be a higher priority than attaining the "feeling of being listened to." 
Along the same lines, according to Chovil (1991), nonverbals can have a secondary (or additional information) communicative role. Admittedly, Buck (1991) contradicted Chovil (1991) on this point. Even so, according to Chovil, in a low social situation, where another person is not physically present, even though the subject was instructed to imagine another person present, the subject made fewer physical displays as compared to a face-toface interaction. In other words, the need to give facial feedback seems to be easily satisfied at a lower level when the listener is imagining a speaker present or has a decrease in attention to his or her awareness of nonverbal cues, because of the absence of a real person. In the same way, it is possible that the subjects in this study who imagined themselves to be the speaker were satisfied with the listeners' level of feedback behavior. Simply put, perhaps all speakers really want in a social situation is to have people remain in proximity so that the speaker does not appear to be talking to him- or herself.

Another reason for the findings of this research may be the speaker's perception of listener intensity. The intensity indicators that were observed as a particular level of eye contact, head nods, or vocalics of these listener feedback behaviors may have been sufficient for the speakers, even when absent in a condition. For example, Halberstadt (1986) reported that family socialization influences the individual's ability to encode and decode nonverbal behavior accurately, requiring differing levels of intensity depending upon the family socialization process. Her research findings showed that individuals socialized in a family environment that is low in expressiveness or not valuing emotional displays requires that the "individuals must become sensitive to the most subtle displays of emotion in order to relate effectively with other family members" (p. 827). It has been found that such socialization increases sensitivity to the nonverbal displays of others, which improves skill in judging nonverbal cues (Lanzetta and Kleck, 1970, p. 18). Perhaps more families are producing individuals who are well-socialized as low expressives who have learned to perceive and be satisfied with a lower intensity and 
frequency of listener nonverbal feedback behaviors than the literature and pilot study would actually lead us to think.

The research findings of this study may also be attributed to the perception of the speaker-subject. Kennamer (1990) argued that individuals are not very accurate in their perceptions of the opinions of others. A speaker may think he or she is being listened to just because he or she thinks the listener is of the opinion that the speaker is a good speaker. Kennamer's perspective as a symbolic interactionist is to view the perceptions of individuals as being subjectively reflected appraisals that others are assumed to have, rather than the actual evaluations by others.

Concerning the findings of eye contact in this study, Mulac, Studley, Wiemann and Bradac (1987) reported that men use eye gaze less than women and that women defer to less eye gaze when they are with men than when they are in female/female dyads. Therefore, less eye gaze/eye contact is known to be more comfortable for men, and women are willing to accept and adapt to it. In much the same way, speakers may be accepting and adapting to whatever nonverbal listener feedback they receive.

Fishbein (1967), an integration theorist, discussed the interactive nature of attitudes as it relates to expectancy-value theory. Specifically relevant to our discussion is the concept of beliefs being expectancies and attitudes being evaluative and learned. In this context, when new learning takes place, attitudes may change. Therefore, another explanation for the findings of this study may be that everyday communication experiences are training communicators to modify their communication expectations. In this case, perhaps speakers are learning to accept a lower level of listener nonverbal feedback. In the context of everyday communication that lacks a deliberate focus on monitoring listener nonverbal feedback behaviors, higher intensities of listener feedback may be just communication "plusses" for the speaker's "feeling" of being listened to. 
Along the same lines, another explanation for this study's findings may be found in the work of Palmgreen (1984), who provides a gratifications approach, based on expectancy-value theory. He presented a cyclical view of the process of seeking gratification, in which the individual's entire belief set and evaluations are taken into account. As the individual seeks gratification, he or she learns from each experience, which in turn molds or modifies each subsequent search for gratification. For example, some individuals talk back to the television set because they need to say something. But they never expect to be heard or feel listened to, yet a non-response does not stop them from talking to the "tube" and receiving speaker gratification for having spoken their "piece" so well. They do not expect more from the television, and therefore, they will continue to repeat the non-response "interaction" because they are gratified simply by their speaking. It may be that speakers feel gratified because they are imagining themselves to be speaking and the listener nonverbal feedback behaviors are irrelevant.

Another explanation may be that speakers tend to focus on speaking and are not usually focusing on feeling listened to. Some examples are found in our academic and professional training: speaking to inform, focusing on wanting to dispense information; speaking to entertain, focusing on wanting to send amusement, and; speaking to persuade, focusing on wanting to expound arguments. While some communication textbooks devote an entire chapter to listening, much less attention is given to reading audience response during an oral presentation, and little or no such training takes place for social, dyadic interaction. For example, for speaking casually, Nelson and Pearson (1990) gave more space than is found in most textbooks by devoting one paragraph each to audience adaptation and audience feedback, along with one summary sentence: "Watch your classmates so that you can learn to imitate the good things they do and avoid the problems they exhibit" (p. 15). Therefore, in social dyadic interactions, speakers may not be 
sufficiently trained to watch for listener nonverbal feedback behaviors, either by textbook readings, classroom exercises, or personal experience.

Another possible reason for the findings may be based on Ralph Schoenstein, “Time Lurches On" reprinted in "Looking Out Looking In" (Adler \& Towne, 1990, p. 249). His concept is that "If you are well enough to be talking, people consider your condition superb, even if you colorfully describe an internal hemorrhage" as your reply to their "How are you?" Schoenstein points out that, "There is no known way to shake the composure of the man who makes a perfunctory inquiry about your health; he loves his lines so well that the grimmest truth can't make him reverse them." For example:

HE: How are you?

ME: I'll be dead in a week!

HE: Glad to hear it. Take care now!

In this case, the speaker is so without solicitude that he is not paying attention to his listener's verbal reply in the form of words, and he probably is not paying attention to his listener's nonverbal reply in the form of eye contact, head nods, and vocalics. Perhaps speaker-subjects in this study were so indifferent that they performed their role of speaker as merely a form or superficial routine.

According to the literature, there are many types of non-listening. Pseudolistening is one type of non-listening, and is an imitation, counterfeit, polite mask that ignores the speaker's remarks (Adler \& Towne, 1990). Speakers may be trained to accept the counterfeit, polite mask of a listener, because it is better than not having a listener. Stagehogging, another type of non-listening, is used by speakers who allow you to speak from time to time, but only so that they can take a breath, use your remarks as a basis for their own babbling, or keep you from running away (Adler \& Towne, 1990). Again, what will speakers allow in listener behavior, just to keep the listener from running away? Yet another type of non-listening is selective listening, which screens out what the listeners are 
disinterested in. Selective listeners respond only to the parts of the speakers' remarks that interest them (Adler \& Towne, 1990). Perhaps speakers are patiently waiting for listeners to stop screening and find something of interest in the message that the listener can respond to. The insulated listening form of non-listening is used by listeners who fail to hear or acknowledge and promptly forget what the speaker has said (Adler \& Towne, 1990). Speakers may be trained to accept such listener behavior and not make note of it as being insufficient because it does not flagrantly violate the speaker's own expectations, practices, or personal norms.

The literature discusses many reasons for not listening and why individuals do not care if others listen. Message overload may give listeners too much input to concentrate on so that the listener lets his or her attention wander from the listener role and his or her responses to the speaker. Then the listener may begin to focus on his or her upcoming speaking response to the speaker's message rather than on giving appropriate listener feedback (Adler \& Towne, 1990). Preoccupation is another reason we do not care if others listen. Because we are "wrapped up in personal concerns that are of more immediate importance to us than the messages (feedback) others are sending" (Adler \& Towne, 1990, p. 253) to us, when we are speakers we do not care if others listen.

Rapid thought can also have an impact on our listening and our attention toward speakers. We can only verbalize somewhere between $125-150$ words per minute, but can think at rates of 500 words per minute (Wolvin \& Coakley, 1992). The temptation is to use the surplus time gained, while waiting for the the speaker's words to be processed in the listener's mind, in ways that relate to our ideas as upcoming speakers and not to appropriate listener feedback.

In addition, effort is required for both listening and speaking. Speaking is hard work (Adler \& Towne, 1990, p. 254), and is equal to physical effort that may make it more difficult for speakers to monitor the nonverbal feedback behaviors of listeners. There are 
many factors that contribute to distractions and preoccupations experienced by the speaker that interfere with monitoring or even having an interest in the listener's nonverbal feedback behavior. Just having someone near who does not interrupt may be enough for most social interactions.

\section{Suggestions for Future Research}

The results of this study are unique to its situation, population, and design. However, in light of the literature reviewed and the results of this study, some old and new questions and suggestions for experimental research are raised.

One suggestion begins as a question regarding the validity of prior research results and brings into question research methods. If researchers expect to generalize their experimental research results, then they may be forced to create more authentic situations or move into the field. For example, Halberstadt (1986) discussed the artificiality of subject's posing for encoding following the experimenter's explicit instructions and in full knowledge of being recorded (Feleky, 1914; Levy, 1964; Zuckerman, Lipets, Koivumaki \& Rosenthal, 1975). Halberstadt's concern is shared by this researcher, in that the subjects were cued to perform at an optimal skill level while consciously communicating, "But it may not determine how a subject would ever actually communicate naturally" (p. 830).

Ekman (1965) clearly stated that earlier findings were obtained in a "haphazard" (p. 726) manner with methodological problems that are far from solved and often ignored. He continued by pointing to the contrast of more recent studies conducting experiments as nonverbal behavior occurs spontaneously during an interpersonal relationship. Even so, he acknowledged the inherent artificiality of using photographs in his study. Therefore, for this and other reasons, he cautiond the reader that the results should be taken as tentative.

Therefore, it is suggested that future research investigate nonverbal feedback behaviors in natural environments. Subjects could then be observed in uncontrived 
situations. People could be observed where they usually communicate and with whom they usually communicate. Even the finest laboratory setting and the best trained confederate are still artificial and not a real experience. Therefore, manipulations and laboratories should be used with caution when researching nonverbal feedback behaviors.

Another tactic may be to measure more than listener nonverbal feedback behaviors. A broader approach may reveal what other factors play a part in the speaker's feelings of being listened to and understood. Research based on the interdependence of a variety of variables, in addition to nonverbal feedback behaviors, may confirm the findings of this research, that nonverbal feedback behaviors may have been overrated in their potential to signal cues that cause speakers to feel listened to or understood. If other variables are added to the model in Figure 1, the model may present a more accurate picture of what affects the feeling states of being listened to and understood. Some other variables may include relationship levels, message content, and speaker expectations.

\section{CONCLUSIONS AND SUGGESTIONS}

While omitted, unmeasured variables may have affected the results of this study. The practicality of isolating particular nonverbal feedback behaviors in experimental situations may be questionable, since it involves extracting from the whole what may be interdependent variables. It may not be possible to measure accurately the effects of nonverbal feedback behaviors in a controlled laboratory environment. The difficulty may not be with the laboratory environment alone or with the extracting of particular nonverbal feedback behaviors or even with the best of research designs. When all of the minor limitations are combined they may have a synergistic effect, increasing the potency of the combined limitations geometrically, rather than arithmetically. The compounding of limitations may result in inaccurate experimental research results and misinterpretations. 
Even so, Borden, Gregg and Grove (1969) argued that it is necessary for the communicator to separate stimuli so that one set of stimuli does not affect the interpretation of another set of stimuli. They discussed and warned us about the complexity of processing internal and external stimuli in manageable quantities or "our nervous system breaks down" (p. 9). It is a fact that a communication experience is comprised of interdependent variables.

Much more than eye contact, vocalics, and head nods may be bombarding the individual while he or she is attempting to separate internal and external stimuli that contribute to feeling listened to or understood. There are things that would be useful to include, but which the nonverbal and listening literature leaves out. For example, the literature omits relating concepts, such as relevance and attribution. Future models may want to include more variables, including race and culture.

When isolated, listener nonverbal feedback behaviors may be overrated in their effect on the speaker's "feeling of being listened to" and the speaker's "feeling of being understood." However, this researcher still maintains the belief that there is more to feeling listened to or understood than the erratic eruption of a spontaneous emotion. Whether or not we are able to discover the exact ingredients and specific amounts used to concoct the "feeling of being listened to" and the "feeling of being understood" may not be as important as knowing that individuals will continue to strive to listen and understand, and may, along the way, give the speaker an added gift of experiencing those feeling states.

It is not surprising that researchers have not yet presented the world with the complete and perfect directions for repeated communication success--the recipe is not that easy to identify. 


\section{REFERENCES}

Abrams, L. J. (1989, November). Feeling understood/misunderstood and satisfaction in the physician-patient interaction. A paper presented at the annual convention of the Speech Communication Association.

Adler, R. B., \& Towne, N. (1990). Looking out looking in (6th ed.). Fort Worth: Holt, Rinehart and Winston.

Andersen, P. A. (1984). Nonverbal communication in the small group. In R. S. Cathcart and I. A. Samovar (Eds.) Small group communication (4th ed.). Dubuque, IA: William C. Brown Publishers.

Andersen, P. A., \& Bowman, L. (1985). Positions of power: Nonverbal cues of status and dominance in organizational communication. Paper presented at the annual convention of International Communication Association, Honolulu, HI.

Archer, D., \& Akert, R. M. (1977). Words and everything else: Verbal and nonverbal cues in social interpretation. Journal of Personality and Social Psychology, 35, 443-449.

Argyle, M. (1970). Eye-contact and distance: A reply to Stephenson and Rutter. British Journal of Psychology, 61, 395-396.

Argyle, M., \& Cook, M. (1976). Gaze and mutual gaze. Cambridge: Cambridge University Press.

Argyle, M., \& Dean, J. (1965). Eye-contact, distance and affiliation. Sociometry, $28,289-304$.

Barker, L. (1984). Communication. Englewood Cliffs, NJ: Prentice Hall.

Berger, C., \& Calabrese, R. (1975). Some explorations in initial interaction and beyond: Toward a development theory of interpersonal communication. Human Communication Research, 1, 99-112.

Birdwhistell, R. L. (1955). Background to kinesics. ETC, 13, 10-18.

Birdwhistell, R. L. (1970). Kinesics and context. Philadelphia: University of Pennsylvania Publications.

Borden, G. A., Gregg, R. B., Grove, T. G. (1969). Speech behavior and human interaction. Englewood Cliffs, NJ: Prentice-Hall.

Bostrom, R. N., \& Waldhart, E. S. (1980). The Kentucky comprehensive listening test. Lexington: University of Kentucky. 
Brooks, C. I., Church, M. A., \& Fraser, L. (1986). Effects of duration of eye contact on judgments of personality characteristics. Journal of Social Psychology, 126, 71-78.

Brown, L. (1982). Communicating facts and ideas in business. Englewood Cliffs, NJ: Prentice-Hall.

Brown, J., \& Carlsen, G. (1955). Brown-Carlsen listening comprehension test, manual of directions. Yonkers-on-the-Hudson, NY: World Book.

Brownell, J. (1990). Perceptions of effective listeners: A management study. Journal of Business Communication, 27, 401-415.

Buck, R. (1991). Social factors in facial display and communication: A reply to Chovil and others. Journal of Nonverbal Behavior, 15, 155-161.

Burgoon, J. K., Buller, D. B., \& Woodall, W. G. (1989). Nonverbal communication: The unspoken dialogue. New York: Harper \& Row.

Cahn, D. D. (1981, April). Feeling understood as a research concept: An alternative to empathy. Paper presented at the annual convention of the Central States Speech Association held in Chicago.

Cahn, D. D. (1983). Relative importance of perceived understanding in initial interaction and development of interpersonal relationships. Psychological Reports, 53, 923-929.

Cahn, D. D. (1984). Relative importance of perceived understanding in students' evaluation of teachers. Perceptual and Motor skills, 59, 610.

Cahn, D. D. (1985). Communication and the feeling of being understood. Informatologia Yugoslavica, 17(1-2), 191-199,

Cahn, D. D. (1986). Perceived understanding, supervisor-subordinate communication, and organizational effectiveness. Central States Speech Journal, 37, 19-26.

Cahn, D. D. (1987a). Letting go: A practical theory of relationship disengagement and reengagement. New York: SUNY Press.

Cahn, D. D. (1987b, August). The relationship of perceived understanding to interpersonal attitudes and communication behavior. Paper presented at the 37th Biennial Convention of the World Communication Association, University of East Anglia, Norwich, England.

Cahn, D. D. (1989). Relative importance of perceived understanding in developing male-female mate relationships. Psychological Reports, 64, 1339-1342.

Cahn, D. D., \& Frey, L. R. (1989). Behavioral impressions associated with perceived understanding. Perceptual and Motor Skills, 69, 1299-1302. 
Cahn, D. D., \& Shulman, G. M. (1984). The perceived understanding instrument. Communication Research Reports, 1, 122-125.

Caplan, F. (1973). The first twelve months of life. New York: Grosset \& Dunlap.

Chovil, N. (1991). Social determinants of facial displays. Journal of Nonverbal Behavior, 15, 141-154.

Chovil, N., \& Fridlund, A. J. (1991). Why emotionality cannot equal sociality: Reply to Buck. Journal of Nonverbal Behavior, 15, 163-167.

Cissna, K., \& Sieburg, E. (1986). Patterns of interactional confirmation and disconfirmation. In J. Stewart Bridges not walls (4th ed.). New York: Random House.

Coakley, C. G., \& Wolvin, A. D. (1990). Listening theory and research: The state of the art. Journal of the International Listening Association, 4, 33-61.

Combs, A. W., \& Snygg, D. (1959). Individual behavior: A perceptual approach to behavior. New York: Harper \& Row.

Cushman, D., \& Cahn, D. (1985). Communication in interpersonal relationships. New York: SUNY Press.

Dittmann, A. T. (1972a). The body movement-speech rhythm relationship as a cue to speech encoding. In A. W. Siegman and B. Pope (Eds.) Studies in dyadic communication. New York: Pergamon Press.

Dittmann, A. T. (1972b). Development factors in conversational behavior. Journal of Communication, 22, 404-423.

Ekman, P. (1965). Differential communication of affect by head and body cues. Journal of Personality and Social Psychology, 2, 726-735.

Ekman, P. (1985). Telling lies: Clues to deceit in the marketplace, politics, and marriage. New York: Norton.

Ekman, P., \& Friesen, W. V. (1967). Head and body cues in the judgment of emotion: A reformulation. Perceptual and Motor Skills, 24, 711-724.

Facione, P. (1973). Meaning and intending. American Philosophical Quarterly, 10, 277-287.

Feleky, A. M. (1914). The expression of the emotions. Psychological Review, 21, 33-41.

Feldstein, S., \& Bond, R. N. (1982, April). Interpersonal perception in conversational interactions as a function of self-perception. Paper presented at the annual meeting of the Eastern Psychological Association, Baltimore, MD. 
Fishbein, M. (1967). A behavior theory approach to the relations between beliefs about an object and the attitude toward the object. In M. Fishbein (Ed.) Readings in attitude theory and measurement (pp. 389-400). New York: John Wiley.

Gitter, A. G., Black, H., \& Fishman, J. E. (1975). Effect of race, sex, nonverbal communication and verbal communication on perception of leadership. Sociology and Social Research, 60, 46-57.

Grice, H. P. (1975). Logic and conversation. In P. Cole and J. Morgan (Eds.) Syntax and semantics (Vol. 3, pp. 41-58). New York: Academic Press.

Gudykunst, W. B., Kim, Y. Y. (1984). Communicating with strangers: An approach to intercultural communication. New York: Random House.

Haase, R. F., \& Tepper, D. T., Jr. (1972). Nonverbal components of empathetic communication. Journal of Counseling Psychology, 19, 417-424.

Halberstadt, A. G. (1986). Family Socialization of emotional expression and nonverbal communication styles and skills. Journal of Personality and Social Psychology, 51, 827-836.

Harris, R. M., \& Rubenstein, D. (1975). Paralanguage, communication, and cognition. In A. Endon, R. M. Harris, \& M. R. Key (Eds.), Organization of behavior in face-to-face interaction (pp. 251-276). Chicago: Aldine.

Heider, F. (1958). The psychology of interpersonal relations. New York: John Wiley.

Keefe, W. F. (1971). Listen, management! New York: McGraw-Hill.

Keeley-Dyreson, M., Burgoon, J. K., \& Bailey, W. (1991). The effects of stress and gender on nonverbal decoding accuracy in kinesic and vocal channels. Human Communication Research, 17, 584-605.

Kelley, H. (1973). The processes of causal attribution. American Psychologist, 28, 107-128.

Kendon, A. (1970). Movement coordination in social interaction: Some examples described. Acta Psychologica, 32, 100-125.

Kennamer, J. D. (1990). Self-serving biases in perceiving the opinions of others: Implications for the spiral of silence. Communication Research, 17, 393404.

Kleinke, C. L. (1986). Gaze and eye contact: A research review. Psychological Bulletin, 100, 78-100.

Laing, R., Phillipson, H., \& Lee, A. (1966). Interpersonal perception. New York: Springer. 
Lanzetta, J. T., \& Kleck, R. E. (1970). Encoding and decoding of nonverbal affect in humans. Journal of Personality and Social Psychology, 16, 12-19.

Levy, P. K. (1964). The ability to express and perceive vocal communications of feeling. In J. Davitz (Ed.) The communication of emotional meaning (pp. 43-55). New York: McGraw-Hill.

Littlejohn, S. W. (1989). Theories of human communication (3rd ed.). Belmont, CA: Wadsworth Publishing.

McCaskey, M. B. (1978). Place, imagery, and nonverbal clues. In A. G. Athos and J. J. Gabarro (Eds.), Interpersonal behavior (pp. 63-73). Englewood Cliffs, NJ: Prentice-Hall.

Mead, G. H. (1934). Mind, self, and society. Chicago: University of Chicago Press.

Mehrabian, A., \& Wiener, M. (1967). Decoding of inconsistent communications. Journal of Personality and Social Psychology, 6, 109-114.

Menyuk, P. (1971). The acquisition and development of language. Englewood Cliffs, NJ: Prentice-Hall.

Menyuk, P. (1972). The development of speech. New York: Bobbs-Merrill.

Mills, E. P. (1974). Listening: Key to communication. New York: Petrocelli.

Mulac, A., Studley, L. B., Wiemann, \& Bradac, J. J. (1987). Male/female gaze in same-sex and mixed-sex dyads: Gender-linked differences and mutual influence. Human Communication Research, 13, 323-343.

Nelson, P. E., Pearson, J. C. (1990). Confidence in public speaking (4th ed.). Dubuque, IA: William C. Brown Publishers.

Palmgreen, P. (1984). Uses and gratifications: A theoretical perspective. In R. N. Bostrom (Ed.) Communication yearbook 8 (pp. 20-55). Beverly Hills: Sage Publications.

Pearson, J. C., \& Nelson, P. E. (1988). Understanding and sharing: An introduction to speech communication (4th ed.). Dubuque, IA: William C. Brown Publishers.

Phillips, G. M., \& Metzgar, N. J. (1976). Intimate communication. Boston: Allyn and Bacon.

Philpott, J. S. (1983). The relative contribution to meaning of verbal and nonverbal channels of communication: A meta-analysis. Unpublished master's thesis, University of Nebraska.

Rankin, P. T. (1926). The measurement of the ability to understand spoken language. Unpublished doctoral dissertation, University of Michigan. 
Rhodes, S. C., Watson, K. W., \& Barker, L. L. (1990). Listening theory and research: The state of the art. Journal of the International Listening Association, 4, 62-82.

Ritchie, L. D. (1991). Communication concepts 2: Information. Newbury Park, CA: Sage.

Roberts, M. (1987). No language but a cry. Psychology Today, 21, 57-58.

Roedell, W. C., \& Slaby, R. G. (1977). The role of distal and proximal interaction in infant social preference formation. Developmental Psychology, 13, 266273.

Rogers, C. R. (1951). Client-centered therapy. Boston: Houghton Mifflin.

Rosenfeld, H. M. (1966). Approval-seeking and approval-inducing functions of verbal and nonverbal responses in the dyad. Journal of Personality and Social Psychology, 4, 65-72.

Rosenfeld, H. M. (1978). Conversational control functions of nonverbal behavior. In A. W. Siegman and S. Feldstein (Eds.) Nonverbal behavior and communication (pp. 291-328). Hillsdale, NJ: Earlbaum.

Rosenstock-Huessy, E. (1970). Speech and reality. Norwich.

Ross, L. (1977). The intuitive psychologist and his shortcomings: Distortions in the attribution process. In L. Berkowit (Ed.) Advances in experimental social psychology. New York: Academic Press.

Rubin, R. B. (1982a). Assessing speaking and listening competency at the college level: The communication competency assessment instrument. Communication Education, 31, 19-31.

Rubin, R. B. (1982b). The communication competency assessment instrument. Annandale, VA: Speech Communication Association.

Rubin, R. B. \& Roberts, C. V. (1987). A comparative examination and analysis of three listening tests. Communication Education, 36, 142-153.

Scherer, K. R., Koiwunaki, J., \& Rosenthal, R. (1972). Minimal cues in the vocal communication of affect: Judging emotions from content-masked speech. Journal of Psycholinguistic Speech, 1, 269-285.

Searle, J. (1970). Speech acts. Cambridge: Cambridge University.

Seay, T. A., \& Altekruse, M. K. (1979). Verbal and 40 nonverbal behavior in judgments of facilitative conditions. Journal of Counseling Psychology, 26, 108-119. 
Shulman, G. M., \& Fuller, L. (1981, April). The construction and assessment of a preliminary instrument to measure the feeling of being understood/misunderstood. Paper presented at the meeting of the Central States Speech Association, Chicago, IL.

Smith, H. J., Archer, D, \& Costanzo, M. (1991). "Just a hunch": Accuracy and awareness in person perception. Journal of Nonverbal Behavior, 15, 3-18.

Snyder, W. U. (1945). An investigation of the nature of non-directive psychotherapy. Journal of General Psychology, 33, 193-223.

Sperber, D., \& Wilson, D. (1986). Relevance: Communication and cognition. Cambridge, MA: Harvard University Press.

Spitz, R. A. (1965). The first year of life: A psychoanalytic study of normal and deviant development of object relations. New York: International Universities Press.

Starkweather, J. A. (1961). Vocal communication of personality and human feeling. Journal of Communication, 11, 69.

Steil, L. K., Barker, L. L., \& Watson, K. W. (1983). Effective listening: Key to your success. Reading, MA: Addison-Wesley.

Steil, L. K., Summerfield, J., \& de Mare, G. (1983). Listening: It can change your life. New York: John Wiley \& Sons.

Stephenson, G. M., \& Rutter, D. R. (1970). Eye-contact, distance and affiliation: A re-evaluation. British Journal of Psychology, 61, 385-393.

Tannen, D. (1986, October 12). Did you say what I just heard? The Washington Post, p. D3.

Tannen, D. (1990, June 24). Sex, lies, and conversation. The Washington Post, p. C3.

Tepper, D. T., Jr., \& Haase, R. F. (1978). Verbal and nonverbal communication of facilitative conditions. Journal of Counseling Psychology, 25, 35-44.

von Cranach, M., \& Ellgring, J. H. (1973). Problems in the recognition of gaze direction. In M. von Cranach and I. Vine (Eds.) Social communication and movement (pp. 419-443). New York: Academic Press.

von Wright, G. (1971). Explanation and understanding. Ithica, NY: Cornell University.

Watson, K. W., \& Barker, L. L. (1983). Watson-Barker listening test. Auburn, AL: Spectra.

Watzlawick, P., Beavin, J. H., \& Jackson, D. D. (1967). Pragmatics of human communication: A study of interactional patterns, pathologies, and paradoxes. New York: W. W. Norton. 
Weaver, C. H. (1972). Human listening: Processes and behavior. Indianapolis: Bobbs-Merril.

Weinrauch, J. D., Swanda, Jr., J. R. (1975). Examining the significance of listening: An exploratory study of contemporary management. Journal of Business Communication, 13, 25-32.

Witkin, B. R. (1990). Listening theory and research: The state of the art. Journal of the International Listening Association, 4, 7-32.

Wolvin, A., \& Coakley, C. G. (1982). Listening. Dubuque, IA: William C. Brown Publishers.

Wolvin, A., \& Coakley, C. G. (1988). Listening (3rd ed.). Dubuque, IA: William C. Brown Publishers.

Wolvin, A., \& Coakley, C. G. (1992). Listening (4th ed.). Dubuque, IA: William C. Brown Publishers.

Wood, B. S. (1981). Children and communication: Verbal and nonverbal language development (2nd ed.). Englewood Cliffs, NJ: Prentice-Hall.

Zahn, G. L. (1973). Cognitive integration of verbal and vocal information in spoken sentences. Journal of Experimental Social Psychology, 9, 320-334.

Zuckerman, M., Lipets, M. S., Koivumaki, J. H., \& Rosenthal, R. (1975). Encoding and decoding nonverbal cues of emotion. Journal of Personality and Social Psychology, 32, 1068-1076. 
APPENDIX A

PILOT STUDY QUESTIONNAIRE 


\section{PILOT STUDY QUESTIONNAIRE}

Your confidential answers to the following questions will be used in the development of a questionnaire to be used in conjunction with my graduate thesis. Your candid responses will be greatly appreciated.

1. When you speak to someone, what does that person do that causes you to feel that that person is listening to you?

2. When someone speaks to you, what do you do that causes that person to feel that you are listening?

3. When you speak to someone, what does that person do that causes you to feel that that person is NOT listening to you?

4. When someone speaks to you, what do you do that causes that person to feel that you are NOT listening?

Thank you for your help! I would also really appreciate it if you could complete the following demographic information.

Age __ Sex___ Regular Occupation

Race or Ethnic Group Last Grade Completed

Where do you live? City State

Where did you grow up? 
APPENDIX B

PERCEIVED LISTENING INSTRUMENT 


\section{PERCEIVED LISTENING INSTRUMENT}

INSTRUCTIONS: You have just viewed a videotaped communication experience in which you placed yourself in the role of the speaker. Please indicate the extent to which each statement describes how you felt when imagining yourself as the speaker.
(1) Strongly Disagree
(2) Disagree Somewhat
(3) Unsure
(4) Agree Somewhat
(5) Strongly Agree

1. The story was well told.

2. The listener did not understand the story.

3. I felt that the listener was really listening.

4. The story was not relevant to the listener.

5. The listener understood the story.

6. The listener made a conscious effort to hear the story.

7. I think that the listener enjoyed the story.

8. I felt uncomfortable because of the listener.

9. The listener paid close attention to the story.

10. The listener was interested in the story.

11. The listener was not a good listener.

12. I was able to understand the story.

13. I felt comfortable with the listener.

14. The listener should have been listening better.

15. The listener really understood me.

16. The story could have been told better.

17. The listener gave undivided attention to me.

18. The listener did not understand me.

19. The story was relevant to me.

20. The listener made me feel like I was understood. 
APPENDIX C

PERCEIVED UNDERSTANDING INSTRUMENT 


\section{PERCEIVED UNDERSTANDING INSTRUMENT}

INSTRUCTIONS: You have just finished watching a video while imagining yourself to be the speaker. Please indicate the extent to which each term describes how you felt when imagining yourself as the speaker.
(1) Very Little
(2) Little
(3) Some
(4) Great
(5) Very Great

\begin{tabular}{ll} 
1. Annoyance \\
2. Satisfaction \\
3. Self-reliance \\
4. Discomfort \\
5. Relaxation \\
6. Shyness \\
\hline 7. Dissatisfaction \\
8. Pleasure \\
9. Enviousness \\
\hline 10. Insecurity \\
\hline 11. Good \\
12. Attentiveness
\end{tabular}

13. Sadness

14. Acceptance

15. Humbleness

16. Failure

17. Comfortableness

18. Hostility

19. Incompleteness

20. Happiness

21. Compassion

22. Uninterestingness

23. Importance

24. Assertiveness 
APPENDIX D

AUDIO-TAPED INSTRUCTIONS SCRIPT 


\section{AUDIO-TAPED INSTRUCTIONS SCRIPT}

* THANK YOU FOR PARTICIPATING IN THE STUDY OF STORYTELLING.

* THIS CASSETTE MESSAGE IS INTENDED TO GIVE COMPLETE INSTRUCTIONS AND LEAD YOU THROUGH THE RESEARCH PROCESS.

* HOWEVER, IF, YOU HAVE ANY QUESTIONS REGARDING THE INSTRUCTIONS, PLEASE LET THE RESEARCHER KNOW.

* yOUR PARTICIPATION IS ALWAYS VOLUNTARY, AND YOU MAY WITHDRAW AT ANY TIME BY NOTIFYING THE RESEARCHER.

* WE WILL BEGIN BY READING THE "INFORMED CONSENT FORM" ON THE NEXT PAGE. 
INFORMED CONSENT

$\mathrm{I}$, hereby agree to serve as a

subject in the research project on storytelling, conducted by Christine M. Carpenter, under the supervision of Drs. Good, Ritchie, and Poulsen.

I understand that the study involves viewing a videotape, imagining myself to be the speaker, and completing questionnaires.

I understand that possible risks to me associated with this study are primarily a demand on my time and inconvenience, should a scheduling problem arise.

It has been explained to me that the purpose of the study is to learn more about storytelling.

I may not receive any direct benefit from participation in this study, but my participation may help to increase knowledge which may benefit others in the future.

Christine M. Carpenter has offered to answer any questions I may have about the study and what is expected of me in the study. I have been assured that all information I give will be kept confidential and that the identity of all subjects will remain anonymous.

I understand that I am free to withdraw from participation in this study at any time without jeopardizing my course grades or my relationship with Portland State University.

I have read and understand the foregoing information and agree to participate in this study.

Date Signature

If you experience problems that are the result of your participation in this study, please contact the Chair of the Human Subjects Research Review Committee, Office of Grants and Contracts, 345 Cramer Hall, Portland State University, (503) 725-3417. 
* IF YOU UNDERSTAND AND AGREE TO PARTICIPATE, PLEASE COMPLETE THE FORM AND CONTINUE LISTENING TO THIS TAPE.

* IF YOU NEED MORE TIME FOR THIS OR ANY OTHER PART OF THE RESEARCH PROCESS, PLEASE STOP THE TAPE AND RESUME PLAYING WHEN YOU ARE READY.

* NEXT, WE WILL READ AND COMPLETE THE "INFORMATION SHEET." 


\section{INFORMATION SHEET}

Thank you for participating in this research project. The information you provide will be considered confidential and will not be shared with anyone other than the researchers involved in this project. Your personal information will assist in compiling data for more meaningful interpretation of the results. Please circle the following information that most describes your personal situation. Again, thank you for your help.

\section{ACADEMICMAJOR:}

Science

Humanities

Fine Arts

Behavioral Sciences

Business

Computer/Engineering

Social Science

Education

Undecided

COLLEGE CREDITS COMPLETED:

$0-15$ credits

16-30 credits

$31-45$ credits

46-60 credits

Over 60 credits

GRADE POINT AVERAGE:

(4-pt scale)

Under 2.00

2.00-2.49

2.50-2.99

3.00-3.49

$3.50-4.00$

COMMUNICATION COURSES:

No communication courses

1 communication course

2 communication courses

3 communication courses

4 communication courses

5 or more communication courses
PAST SPEAKING EXPERIENCE:

No past speaking experience

Speaking experience in classes

other than speech

Speech Classes

Some speaking experience

outside of speech class

Good amount of speaking experience outside class

AGE:

Under 20

20-24

25-29

30-39

40-50

Over 50

SEX:

Female

Male

MARITAL STATUS:

Married

Engaged

Single

Divorced

Separated

YOUR CULTURAL BACKGROUND

Asian

Black

European

Hispanic

Mediterranean

Other 
* NOW, LET'S READ THE STORY YOU WILL BE HEARING LATER (NO QUESTIONS WILL BE ASKED ABOUT THE SPECIFIC CONTENT OF THE STORY, SO THERE IS NOTHING FOR YOU TO HAVE TO REMEMBER ABOUT THE STORY). 


\section{HAD A DREAM LAST NIGHT!}

I've got to tell you about the dream I had last night! It was SO real! You and I were hiking in the mountains, just the two of us. We were wearing hiking boots and backpacks, so we were really prepared for the hike. We started out hiking in the mountains where there were lots of trees and brush, but the trail was okay and we were enjoying our climb. Suddenly, we ran out of trail and descended down the side of the mountain to the edge of a river. The river had big rocks in it, so we jumped from rock to rock to get across. The water looked dark, deep, and swift, but we weren't afraid or tired. We kept going, crossing back and forth as we ran out of bank on one side of the river or the other. Then, right in front of us, a big, giant boulder came crashing down the mountainside. It caused a rock slide, but we helped each other climb over the pile of rocks so we could keep hiking upstream. Right after we got past the rock slide, more thundering boulders came crashing down in front of us. They filled the air with dust, but none of them hurt us. When the dust settled, we helped each other over the second rock slide and continued on. Suddenly, we were both at a 7/11 store buying coffee. I was really tired. I paid for my coffee and decided to go back and put some cream in it. By the time I met you out in front of the store, the cream curdled my coffee. It was gross and I never got a sip of it. Right then some friends pulled up to the 7/11 store and asked us if we wanted a ride. So we got in and headed back to town with them. We were riding in the back seat and I was trying not to spill my curdled coffee as we were going around the curves. I was straining to see through the dirty windshield when I saw huge boulders come crashing down the side of the mountain right in front of the car. The driver slammed on the brakes and just in time we made a quick stop, almost throwing us from the back seat into the front seat. But I didn't spill the coffee! 
* PLEASE SET ASIDE ALL PAPERWORK SO YOU WILL NOT BE DISTRACTED WHILE VIEWING THE VIDEOTAPE.

* CONTINUE TO LISTEN TO THIS TAPE UNTIL YOU ARE INSTRUCTED TO PUSH THE “STOP” BUTTON ON THE AUDIO-TAPE CASSETTE PLAYER.

* IMMEDIATELY, UPON CONCLUSION OF THE TWO-AND-A-HALF-MINUTE VIDEOTAPED STORY, PLEASE PUSH THE “STOP” BUTTON ON THE VCR, AND NOTIFY THE RESEARCHER THAT YOU ARE READY TO COMPLETE THE QUESTIONNAIRES.

* REMEMBER TO IMAGINE YOURSELF AS THE SPEAKER TELLING THE STORY.

* AGAIN, THANK YOU FOR YOUR PARTICIPATION IN THIS RESEARCH.

* PLEASE PUSH THE “PLAY” BUTTON ON THE VCR, IMMEDIATELY AFTER PUSHING THE “STOP”BUTTON ON THIS AUDIO-CASSETTE PLAYER.

* NOW YOU MAY PUSH THE “STOP” BUTTON ON THIS AUDIO-CASSETTE PLAYER. 
APPENDIX E

INFORMED CONSENT 
INFORMED CONSENT

I, hereby agree to serve as a subject in the research project on storytelling, conducted by Christine M. Carpenter, under the supervision of Drs. Good, Ritchie, and B. Poulsen.

I understand that the study involves viewing a videotape, imagining myself to be the speaker, and completing questionnaires.

I understand that possible risks to me associated with this study are primarily a demand on my time and inconvenience, should a scheduling problem arise.

It has been explained to me that the purpose of the study is to learn more about storytelling.

I may not receive any direct benefit from participation in this study, but my participation may help to increase knowledge which may benefit others in the future.

Christine M. Carpenter has offered to answer any questions I may have about the study and what is expected of me in the study. I have been assured that all information I give will be kept confidential and that the identity of all subjects will remain anonymous.

I understand that I am free to withdraw from participation in this study at any time without jeopardizing my course grades or my relationship with Portland State University.

I have read and understand the foregoing information and agree to participate in this study.

Date Signature

If you experience problems that are the result of your participation in this study, please contact the Chair of the Human Subjects Research Review Committee, Office of Grants and Contracts, 345 Cramer Hall, Portland State University, (503) 725-3417. 


\section{APPENDIX F}

INFORMATION SHEET 


\section{INFORMATION SHEET}

Thank you for participating in this research project. The information you provide will be considered confidential and will not be shared with anyone other than the researchers involved in this project. Your personal information will assist in compiling data for more meaningful interpretation of the results. Please circle the following information that most describes your personal situation. Again, thank you for your help.

\section{ACADEMICMAJOR:}

Science

Humanities

Fine Arts

Behavioral Sciences

Business

Computer/Engineering

Social Science

Education

Undecided

COLLEGE CREDITS COMPLETED:

$0-15$ credits

16-30 credits

31-45 credits

46-60 credits

Over 60 credits

GRADE POINT AVERAGE:

(4-pt scale)

Under 2.00

2.00-2.49

2.50-2.99

3.00-3.49

$3.50-4.00$

COMMUNICATION COURSES:

No communication courses

1 communication course

2 communication courses

3 communication courses

4 communication courses

5 or more communication courses
PAST SPEAKING EXPERIENCE:

No past speaking experience

Speaking experience in classes

other than speech

Speech Classes

Some speaking experience

outside of speech class

Good amount of speaking experience outside class

AGE:

Under 20

20-24

25-29

30-39

40-50

Over 50

SEX:

Female

Male

MARITAL STATUS:

Married

Engaged

Single

Divorced

Separated

YOUR CULTURAL BACKGROUND

Asian

Black

European

Hispanic

Mediterranean

Other 
APPENDIX G

I HAD A DREAM LAST NIGHT! 


\section{HAD A DREAM LAST NIGHT!}

"I've got to tell you about the dream I had last night! It was SO real! You and I were hiking in the mountains, just the two of us. We were wearing hiking boots and backpacks, so we were really prepared for the hike. We started out hiking in the mountains where there were lots of trees and brush, but the trail was okay and we were enjoying our climb. Suddenly, we ran out of trail and descended down the side of the mountain to the edge of a river. The river had big rocks in it, so we jumped from rock to rock to get across. The water looked dark, deep, and swift, but we weren't afraid or tired. We kept going, crossing back and forth as we ran out of bank on one side of the river or the other. Then, right in front of us, a big, giant boulder came crashing down the mountainside. It caused a rock slide, but we helped each other climb over the pile of rocks so we could keep hiking upstream. Right after we got past the rock slide, more thundering boulders came crashing down in front of us. They filled the air with dust, but none of them hurt us. When the dust settled, we helped each other over the second rock slide and continued on. Suddenly, we were both at a 7/11 store buying coffee. I was really tired. I paid for my coffee and decided to go back and put some cream in it. By the time I met you out in front of the store, the cream curdled my coffee. It was gross and I never got a sip of it. Right then some friends pulled up to the $7 / 11$ store and asked us if we wanted a ride. So we got in and headed back to town with them. We were riding in the back seat and I was trying not to spill my curdled coffee as we were going around the curves. I was straining to see through the dirty windshield when I saw huge boulders come crashing down the side of the mountain right in front of the car. The driver slammed on the brakes and just in time we made a quick stop, almost throwing us from the back seat into the front seat. But I didn't spill the coffee!" 


\section{APPENDIX $\mathrm{H}$}

MANIPULATION CHECK QUESTIONNAIRE 


\section{MANIPULATION CHECK QUESTIONNAIRE}

Tape Number Your ID Number

INSTRUCTIONS: Using a scale of 0 to 10 ,

10 being the highest and 0 being the lowest, please answer the following question.

HOW WELL DID THE LISTENER DO AT RESPONDING TO THE SPEAKER WITH: feedback eye contact hand gestures short vocal responses smiles attentiveness head nods leaning forward facial expressions understanding 